\title{
Numerical Simulation of Unstable Rock Failure Mechanisms Through Analysis of Energy Transformations
}

Rennie Kaunda

Colorado School of Mines

Fei Wang ( $\sim$ feiwang225@gmail.com )

Colorado School of Mines

\section{Research}

Keywords: Unstable rock failure, Energy transformation mechanism, Loading system stiffness, Rockburst

Posted Date: April 6th, 2021

DOl: https://doi.org/10.21203/rs.3.rs-389398/v1

License: (c) (i) This work is licensed under a Creative Commons Attribution 4.0 International License.

Read Full License 


\title{
Numerical simulation of unstable rock failure mechanisms through analysis of energy transformations
}

\author{
Rennie Kaunda, Fei Wang* \\ Department of Mining Engineering, Colorado School of Mines, Golden, CO 80401, USA \\ *Corresponding author: Fei Wang (feiwang225@gmail.com)
}

Keywords: Unstable rock failure; Energy transformation mechanism; Loading system stiffness; Rockburst

\begin{abstract}
For rock specimen in uniaxial compression, the energy transformations from elastic strain energy in both the rock and the loading system to plastic strain work in the rock can be identified with the changes in these energy components, whose rates are also useful indicators for distinguishing stable and unstable rock failure. In this study, the influences of the loading system stiffness (LSS), the rock stiffness and the rock brittleness on rock failure modes are examined. The observed energy transformations during rock failure in numerical models are interpreted from an energy perspective. The results show that unstable rock failure tends to occur in rock with large brittleness and small stiffness under a soft loading system. A low LSS and rock stiffness will increase the magnitude of stored elastic strain energy before rock failure, while a brittle rock requires less elastic strain energy to be converted plastic strain work than a ductile rock during its failure. This energy-based approach is useful for investigating potential unstable rock failures that could ultimately be applied to analyze complex mine-scale rockburst cases.
\end{abstract}

\section{Introduction}

Understanding the mechanisms of unstable failure is of critical importance to reduce unstable rock failure hazards in deep underground mines and excavations. During a rockburst event, a large amount of pulverized rock can be violently expelled into underground openings, causing injuries or fatalities and disrupting mining activities (Whyatt, J, W. Blake 2002). Many previous experimental studies and numerical simulations have been conducted that focus on the underlying mechanisms of unstable rock failure behaviors (He et al. 2012; Levkovitch et al. 2013; Gu and Ozbay 2015).

Rock failure modes can be classified into stable failure and unstable failure, depending on whether or not a volume of rockmass can consume the energy from its surrounding rockmass during rock failure (Cook 1965; Salamon 1970a, 1984; Rice 1983; Kias and Ozbay 2013; Zhao and Cai 2014). Although many types of unstable rock failure exist in different geological and physical conditions, the general requirements for unstable rock 
failures are brittle material behavior, and a relatively soft loading system (Kaiser and Cai 2012; Walton and Diederichs 2015). Cook and Salamon proved that the rock failure modes were highly dependent on the LSS and the post-peak stiffness of the failed rock. The loading system can vary from a loading machine in the laboratory to the rockmass surrounding an excavation (Cook 1965; Salamon 1970a, 1984). Generally, a steep slope of the postpeak stress-strain curve of a rock specimen can be interpreted to indicate brittle rock behavior, while a gentle slope represents ductile rock behavior (Hajiabdolmajid and Kaiser 2002; Zhang et al. 2016). The LSS affects the amount of elastic strain energy surrounding the target rock, and a relatively soft loading system can therefore store more elastic strain energy and tends to cause unstable rock failure (Beck and Brady 2002). In theory, if the LSS is larger than the post-peak stiffness of the rock material, the rock will fail gradually in a steady and stable mode; however, rock failure will occur in a violent and unstable mode if the LSS is smaller than the post-peak stiffness of the rock (Board et al. 2006; Xu and Cai 2017). From an energy perspective, a high rock material brittleness represents a low capability of dissipating energy during failure, and a soft loading system provides more elastic strain energy to the rock during its failure.

Various laboratory-based experiments have been conducted to analyze the underlying mechanisms of unstable rock failure (Wawersik and Fairhurst 1970; Singh 1987, 1988; Zhao and Cai 2014; Heinze et al. 2015; He et al. 2016a; Kim and Larson 2017; Leveille et al. 2017). To study pillar bursting in the laboratory, Fakhimi et al. designed a steel beam to act as an energy absorber, which was placed between the loading platen and rock specimen (Fakhimi et al. 2016). The stored elastic strain energy in the steel beam could fail the sandstone samples violently, and a maximum rock fragment velocity of over $4 \mathrm{~m} / \mathrm{s}$ was identified using a high-speed camera. A true tri-axial rock test system was designed by $\mathrm{He}$ et al. to simulate strain bursting at a tunnel face (He et al. 2010). The rock was loaded in three mutually perpendicular directions to a pre-defined stress condition, and abrupt unloading in one horizontal direction was used to cause a strain burst. Gong et al. conducted the rockbursting failure within a prefabricated circular hole of cubic granite specimens with high three-dimensional stress conditions in laboratory, where strain burst occurred on the sidewalls tangential to the maximum principal stress direction (Gong et al. 2012).

Numerical simulation of laboratory rock failures and mine-scale rockbursts have been commonly conducted to analyze mechanisms of unstable rock failure (Zubelewicz and Mróz 1983; He et al. 2010; Leveille et al. 2017; Su et al. 2017). Manouchehrian and Cai proposed to use the transferred energy ratio and loading system reaction intensity as indicators to distinguish between stable and unstable failures in a UCS test (Manouchehrian and Cai 2015). Fakhimi et al. found that the rock specimen's diameter and strength had large impact on the ejected velocity of rock fragments, and weakening of the rock by drilling holes in it could reduce the violence of rock failure in numerical models (Fakhimi et al. 2016). Poeck (Poeck 2017) simulated two pillar burst events with mine-scale numerical models based on actual mine cases, and compared the released energy and ground 
subsidence from numerical models with field monitored data to evaluate the reliability of the numerical results. Sainoki and Mitri simulated a fault-slip rockbursting mine in Canada, and they concluded that mining depth, friction angle and fault location had significant impacts on the maximum magnitude and rate of slip displacement along the fault (Sainoki and Mitri 2016).

Vazaios et al. simulated the failure and fracturing process of strain bursting in a circular tunnel with the finite-discrete element method, and ejected rock fragment speed was utilized to estimate the released energy during bursting (Vazaios et al. 2019). Zhu et al. used the Rock Failure Process Analysis (RFPA) code to study the effect of dynamic disturbance on rockburst of underground excavation at depth and the numerical results showed intensity of instability of underground opening increases with the magnitude and prolonged duration of dynamic stress wave (Zhu et al. 2010). Chen et al. simulated true triaxial tests of different rocks and analyzed the critical stress of rock bursts in seven types of rocks with different rock parameters using discontinuous deformation analysis (Chen et al. 2018).

Previous rockbursting studies conducted from an energy perspective have mainly focused on estimating the amount of elastic strain energy prior to rock failure and kinetic energy during failure using analytical method from the stress and strain tensors in numerical models (Gu and Ozbay 2014; He et al. 2016b; Vazaios et al. 2019). Previously, Wang and Kaunda simulated a hypothetical pillar burst in Universal Distinct Element Code (UDEC) software, and the increments in plastic strain work and damped kinetic energy during unstable rock failure were proposed as indicators of rockburst severity (Wang and Kaunda 2019). Although great progress has been made in studying the energy mechanisms of unstable rock failure, the details of energy transformations between different energy components during the rock failure process have still has not been fully explained. The goal of this study is to investigate the energy transformation and indicators of the unstable rock failure in numerical models by integrating energy expressions into the numerical modeling software UDEC. The advantage of this approach is that the magnitudes of different energy components in each zone at every time step can be obtained based on different energy densities and the volume of each zone.

\section{Energy analysis of rock failure}

\subsection{Energy balance in rock}

The energy components considered in this study include elastic strain energy, plastic strain work, total strain energy, and damped kinetic energy; gravitational energy is not considered in this study. Elastic strain energy is one form of stored energy associated with elastic deformation, while plastic strain work and damped kinetic energy are the energy dissipated during rock failure. External work for a volume of rock can result from external forces such as excavation or mining activities, but such work must take the form of elastic strain energy 
within an intact rock volume before it can be dissipated (Andrianopoulos and Manolopoulos 2014). Based on the energy methodology proposed by Salamon (Salamon 1984), the energy balance in Eq. (1) summarizes the conversion between external work $(\Delta \mathrm{W})$, elastic strain energy $\left(\mathrm{W}_{\mathrm{e}}\right)$, plastic strain work $\left(\mathrm{W}_{\mathrm{p}}\right)$, and damped kinetic energy $\left(\mathrm{W}_{\mathrm{d}}\right)$ when rock failure develops and progresses from one state to another. The left- and right-hand sides of in Eq. (1) correspond to the states of energy components within a volume of rock before and after rock failure, respectively.

$$
\Delta \mathrm{W}+W_{e}+W_{\mathrm{p}}+W_{r}=W_{e}{ }^{\prime}+W_{p}{ }^{\prime}+W_{d}{ }^{\prime}
$$

After rearranging the Eq. (1), the energy balance during rock failure can be represented as follows:

$$
\Delta \mathrm{W}+\Delta W_{e}=\Delta W_{p}+\Delta W_{d}
$$

In Eq. (2), the changes in external work and elastic strain energy in a volume of intact rock is equal to the changes in plastic strain energy and released kinetic energy.

For rock failure, the available energy resource is elastic strain energy through elastic deformation, which also could explain why failure also can be defined as the loss of the ability of the material to store elastic strain energy (Andrianopoulos and Manolopoulos 2014; Chen et al. 2017). Rock is anisotropic and behaves both elastically and inelastically during its failure process. Total strain energy is defined as the sum of elastic strain energy and plastic strain work in a volume of rock, and changes in this total quantity indicate the amount of kinetic energy released during unstable rock failure in this study.

\subsection{Energy densities in intact rock}

The elastic strain energy density in a volume of rock can be determined by assuming that the rock has an isotropic elastic behavior (Jaeger, J. C.; Cook, N. G. W.;Zimmerman 2007). The elastic strain energy density of linear isotropic materials undergoing small strains can be written as:

$$
U_{e}=\frac{1}{2 E}\left[{\sigma_{x}}^{2}+{\sigma_{y}}^{2}+{\sigma_{z}}^{2}-2 v\left(\sigma_{x} \sigma_{y}+\sigma_{x} \sigma_{z}+\sigma_{z} \sigma_{y}\right)+2(1+v)\left(\tau_{x y}^{2}+\tau_{x z}^{2}+\tau_{z y}^{2}\right)\right]
$$

Under plane strain conditions, the strain in the third direction (z direction) is zero, so the shear stress components $\tau_{\mathrm{xz}}$ and $\tau_{\mathrm{xz}}$ become zero. Eq. (3) can then be rewritten as

$$
U_{e}=\frac{1}{2 E}\left[\sigma_{x}^{2}+{\sigma_{y}}^{2}+{\sigma_{z}}^{2}-2 v\left(\sigma_{x} \sigma_{y}+\sigma_{x} \sigma_{z}+\sigma_{z} \sigma_{y}\right)+2(1+v) \tau_{x y}{ }^{2}\right]
$$

When the stress and strain condition of a unit volume of rock changes from one state to another state, then as the change is very small, the increment in total strain energy density $\left(\Delta U_{t}\right)$ can be obtained with the average stress tensors and the change in strain tensors. 


$$
\begin{aligned}
\Delta U_{t}=\frac{1}{2}\left[\left(\sigma_{x}+\right.\right. & \left.\sigma_{x}{ }^{\prime}\right) \Delta e_{x}+\left(\sigma_{y}+{\sigma_{y}}^{\prime}\right) \Delta e_{y}+\left(\sigma_{z}+{\sigma_{z}}^{\prime}\right) \Delta e_{z}+\left(\tau_{x y}+\tau_{x y}{ }^{\prime}\right) \Delta \gamma_{x y}+\left(\tau_{x z}+\tau_{x z}{ }^{\prime}\right) \Delta \gamma_{x z} \\
& \left.+\left(\tau_{y z}+\tau_{y z}{ }^{\prime}\right) \Delta \gamma_{y z}\right]
\end{aligned}
$$

Under plane strain condition, the strain components $e_{z}, \gamma_{x z}$ and $\gamma_{y z}$ are zero, so Eq. (5) can then be rewritten as

$$
\Delta U_{t}=\frac{1}{2}\left[\left(\sigma_{x}+\sigma_{x}^{\prime}\right) \Delta e_{x x}+\left(\sigma_{y}+\sigma_{y}^{\prime}\right) \Delta e_{y y}+\left(\tau_{x y}+\tau_{x y}{ }^{\prime}\right) \Delta \gamma_{x y}\right]
$$

The total strain energy density in a volume of rock can be obtained by adding the increase in total strain energy density $\left(\Delta U_{t}\right)$ to its previous total strain energy density $\left(U_{t}^{\prime}\right)$. Before any stress disturbance, total strain energy density is equal to elastic strain energy density at in-situ stress field conditions, so the total strain energy density can be represented as

$$
U_{t}=U_{t}{ }^{\prime}+\Delta U_{t}
$$

Given the total strain energy density $\left(U_{t}\right)$ and elastic strain energy density $\left(U_{e}\right)$ in a unit volume of rock, the plastic strain work density $\left(U_{p}\right)$ is equal to their difference

$$
U_{p}=U_{t}-U_{e}
$$

Damped kinetic energy is the accumulated amount of instantaneous kinetic energy removed from the system in numerical models, which can be considered as a form of cumulative kinetic energy, and it can be several orders of magnitude larger than the current kinetic energy within a model at any given point of time. It should be noted that the instantaneous kinetic energy will be dissipated by the damping coefficient with solution time in numerical models, which is equivalent to the radiated seismicity in the field (Salamon et al. 2003; Sainoki and Mitri 2014; Gu and Ozbay 2015). The released kinetic energy in numerical models accounts for the monitored energy or seismic energy in underground mines (Poeck 2017; Khademian and Ozbay 2018). In this study, the default local damping coefficient of 0.8 in UDEC was used. As the sum of damped kinetic energy for all gridpoints and time, the damped kinetic energy $\left(W_{d-\text { gridpoint }}\right)$ over a time step $(\Delta t)$ at a gridpoint in numerical models is a function of the damping coefficient, the time step and the kinetic energy in the gridpoint ( $W_{k \text {-gridpoint }}$ ), which can be expressed as

$$
W_{d-\text { gridpoint }}=2 \times \alpha \times \Delta t \times W_{k-\text { gridpoint }}
$$




\section{Model Setup}

To study unstable rock failure, the rock properties used during the simulations of UCS tests were obtained from laboratory-based experimental results presented by Zhao and Cai (2015). The granite specimens studied were collected from the Tianhu area in China and were described as Tianhu granite by Zhao and Cai (2015). The geometry, mesh and boundary conditions of the simulated UCS platform are represented in Fig. 1, where the sizes of the rock specimen, steel platen, and loading beam are $50 \mathrm{~mm}$ (width) $\times 100 \mathrm{~mm}$ (height), $54 \mathrm{~mm}$ (width) $\times 4$ $\mathrm{mm}$ (height) and $54 \mathrm{~mm}$ (width) $\times 100 \mathrm{~mm}$ (height), respectively. This simplified platform is utilized to study the contributing factors of unstable rock failure in a UCS test, but both its geometry and parameters cannot be directly compared with the real loading machines in the laboratory. The square zone edge length throughout the entire model is $2 \mathrm{~mm}$, and each square zone has four internal triangular zones.

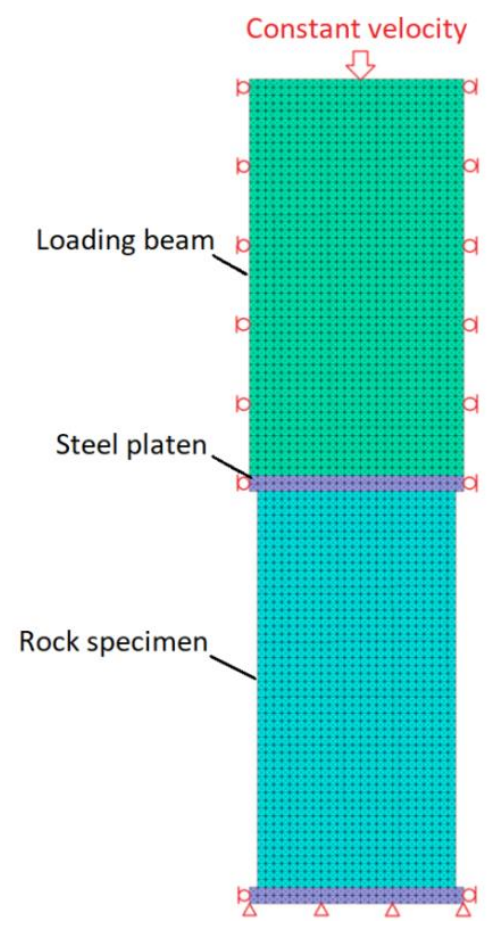

Fig. 1. Geometry, mesh and boundary conditions of the simplified UCS test platform in UDEC.

The bottom of the model was fixed in both the horizontal and vertical directions, but the left and right boundaries of the model were only fixed in the horizontal direction, as shown in Fig. 1. A constant velocity of $0.002 \mathrm{~m} / \mathrm{s}$ was applied to the top boundary of the model, and a time step of $2.0 \times 10^{-8}$ seconds was used for all models in this study. UDEC uses the explicit finite-difference method for numerical analysis, so its solution time cannot be compared with actual physical time. In this case, one second represents fifty million steps due to the time step of $2.0 \times 10^{-8}$ second. Therefore, the numerical loading rate also can be expressed as $4.0 \times 10^{-11} \mathrm{~m} / \mathrm{step}$, which is sufficiently small to fail the rock specimen in a quasi-static manner. Under the quasi-statically loading 
condition, the external work resulting from the top boundary can be assumed to be zero during a short period of solution time, such as during the rapid rock failure process. The friction angle of the contact between the rock specimen and the loading platens is assumed to be zero.

The rock properties presented by Manouchehrian and Cai (2015) were used for parameters of the rock model, and the Mohr-Coulomb model with strain-softening behavior was used as the constitutive law for the Tianhu granite specimen (Table 1). The stiffness of the steel platens was increased by using a small height and an extremely large elastic modulus of $500 \mathrm{GPa}$, and the maximum stored elastic strain energy in these two steel platens was just $4 \mathrm{~J}$ across all the models in this study. This geometry and elastic modulus of the steel platens are designed to minimize the influence of stored elastic strain energy in the steel platens on rock failure modes.

Table 1 Physical and mechanical properties of the Tianhu granite and steel platens [granite data from Zhao and Cai (2015)]

\begin{tabular}{ccc}
\hline Parameter & Granite & Platens \\
\hline Density $(\mathrm{kg} / \mathrm{m} 3)$ & 2650 & 7600 \\
Young's modulus $(\mathrm{GPa})$ & 51 & 500 \\
Poisson's ratio & 0.27 & 0.30 \\
Friction angle $\left(^{\circ}\right)$ & 40 & \\
Tensile Strength $(\mathrm{MPa})$ & 10.2 & \\
\hline
\end{tabular}

The post-peak stress-strain behavior of the Tianhu granite was not obtained by Zhao and Cai (Zhao and Cai 2014) in the laboratory. A convex post-peak stress-strain behavior is observed in the curves of the Tianhu Granite, which may not reflect the post-peak stress strain curves of a typical hard rock. Because no data exist for the post-peak behaviors of the Tianhu Granite, the cohesion-weakening parameters of the granite is adjusted to achieve an unstable rock failure and close-to-zero damped kinetic energy during rock failure under LSS of infinity in Table 2. The cohesion-weakening parameters make the granite specimen behave more ductile than it should be, so that rock failure from stable to unstable can be obtained in the rock specimen under different LSS.

Table 2 Cohesion-weakening parameters of the strain-softening model for the Tianhu granite specimen.

\begin{tabular}{cc}
\hline Plastic shear strain & $\begin{array}{c}\text { Cohesion yield stress } \\
(\mathrm{MPa})\end{array}$ \\
\hline 0 & 37.5 \\
0.001 & 37 \\
0.02 & 32.5 \\
0.08 & 25 \\
\hline
\end{tabular}




\section{Influence of LSS on rock failure modes}

The LSS, determined by elastic modulus and geometry of the loading system, can influence the amount of elastic strain energy stored in the loading system. Since the loading system is simplified into a loading beam in this study, the geometry of the loading system is kept constant. Elastic modulus values of $20 \mathrm{GPa}, 30 \mathrm{GPa}, 40$ GPa and $80 \mathrm{GPa}$ are used for the loading beam to study the influence of LSS on rock failure modes, which can present the general change from unstable rock failure. The LSS value increases with the elastic modulus of the loading system at the same geometry, so a higher elastic modulus of the loading system represents a larger LSS value in this study.

\subsection{Physical behavior of the rock with different LSS}

The stress-strain curves of the Tianhu granite specimen under a loading system with different elastic modulus values are shown in Fig. 2, where the axial strain equals the displacement closure of the two ends of the rock divided by the rock specimen length. The stress-strain curve of the Tianhu specimen under infinitely stiff loading system is also presented to indicate the influence of LSS on post-peak behavior. A convex and ductile post-peak stress-strain curve for the Tianhu granite is obtained with the parameters in Table 2. It is expected that the post-peak rock behavior will facilitate the study of LSS on rock failure modes, but not influence the numerical results of indicators and contributing factors of unstable rock failure in this study.

The same stress-strain behavior can be observed before the rock peak strength, but large differences can be seen in the post-peak stress-strain curves. The rock specimen under a stiffer loading system tends to deviate further from that of infinity and display a steeper post-peak slope, which also has been interpreted as a sign of unstable rock failure in numerical models by some other researchers (Gu and Ozbay 2014, 2015; Manouchehrian and Cai 2015). 


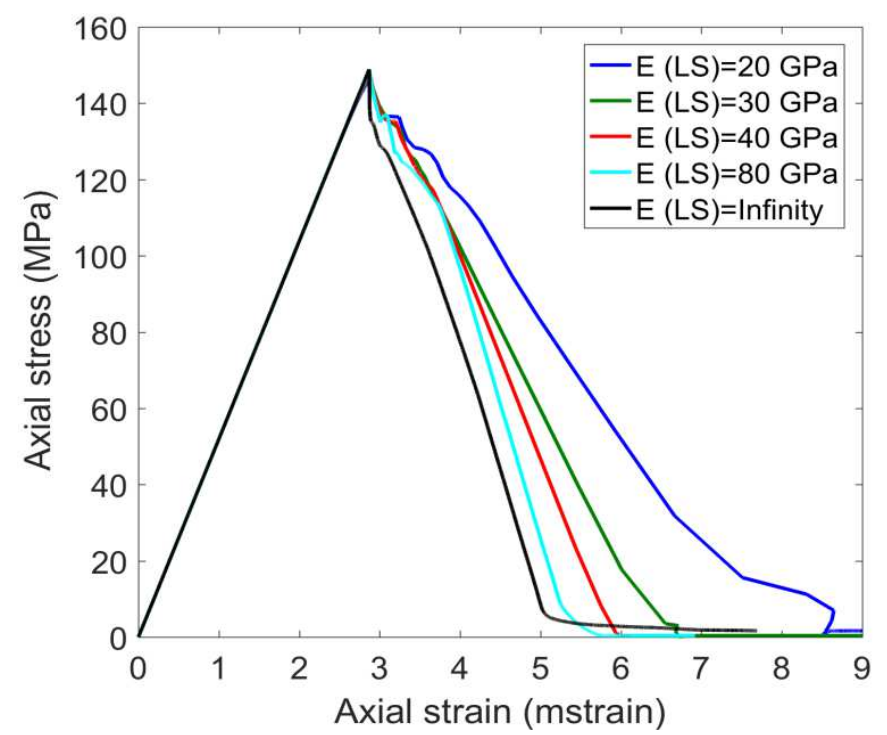

Fig. 2. Stress-strain curves of the Tianhu granite specimen under the loading system with different elastic modulus values.

In Fig. 3, the curves of axial stress with solution time illustrate that rapid stress decrease and strain increase can be seen in the rock specimen under the loading systems with elastic modulus values of $20 \mathrm{GPa}, 30$ $\mathrm{GPa}$ and $40 \mathrm{GPa}$. When the elastic modulus values of the loading system is $80 \mathrm{GPa}$, no large and vertical axial stress decrease and strain increase from the initiation of rock failure to the total loss of rock strength can be observed, suggesting that the rock failure will not develop and progress without the constant external work from the velocity boundary. A linear increase in axial strain with solution time can be observed in all curves after the loss of rock strength, as the displacement closure between two ends of a rock specimen is equivalent to the product of the constant boundary velocity and the solution time.

(a)

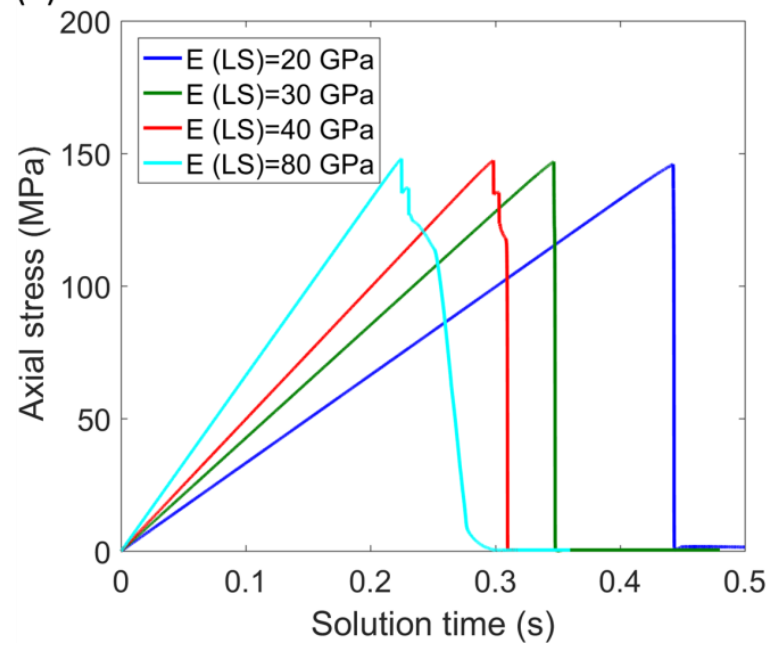

(b)

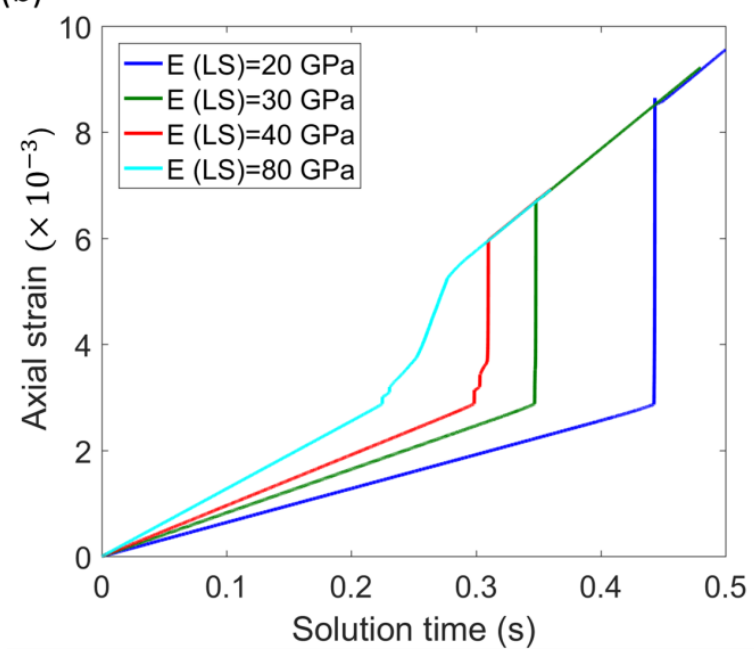

Fig. 3. Stress-strain and stress-time curves of the Tianhu granite specimen under the loading system with different elastic modulus values. 


\subsection{Energy transformations}

The total strain energy, elastic strain energy, and plastic strain work in different sections of the model can be obtained using energy values calculated in each individual zone. The summation of the energy values in the model enables the energy transformations between the rock specimen and its loading system to be analyzed. In Fig. 4, the total strain energy represents the total strain energy in the entire model, and the elastic strain energy in LS (loading system) represents the stored elastic strain energy in the loading system. Conversely, the elastic strain energy in rock and the plastic strain work in rock only cover the corresponding energy components in the rock specimen. Since the loading beam is perfectly elastic, the plastic strain work only exists in the rock due to its strain-softening behavior. The total strain energy equals the sum of elastic strain energy in the LS, elastic strain energy in the rock and plastic strain work in the rock.

The elastic strain energy and plastic strain work increase continually prior to peak stress. Large and rapid decreases within elastic strain energy for both rock and loading system can be observed for the elastic modulus values of $20 \mathrm{GPa}, 30 \mathrm{GPa}$ and $40 \mathrm{GPa}$ during the rock failure process, while plastic strain work increases simultaneously and rapidly. During this rapid process, part of the stored elastic strain energy is dissipated into kinetic energy in the entire model, which can be seen from the rapid decrease in total strain energy. 
(a)

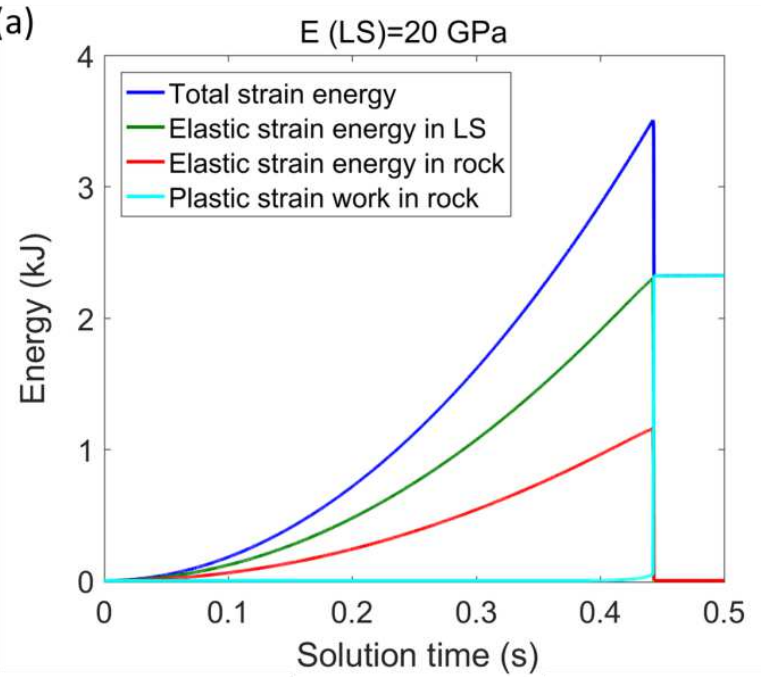

(c)

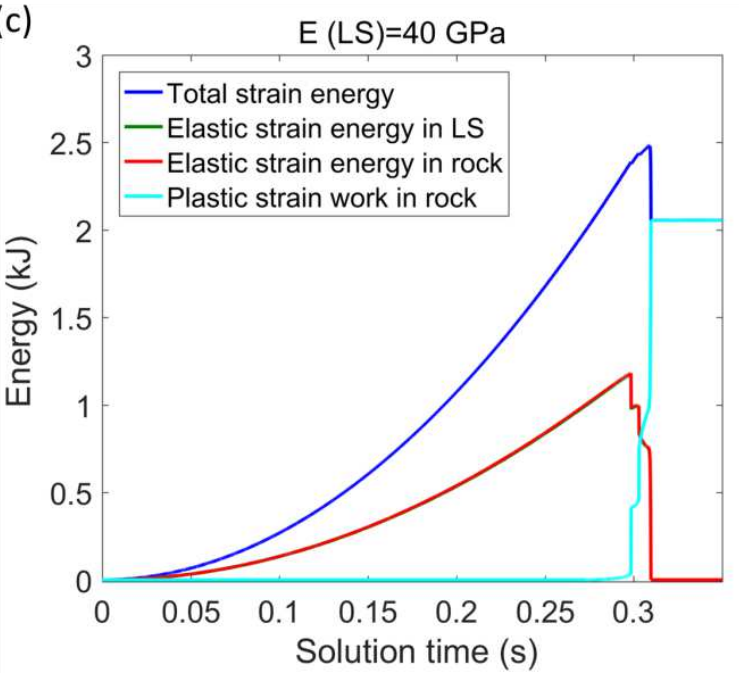

(b)

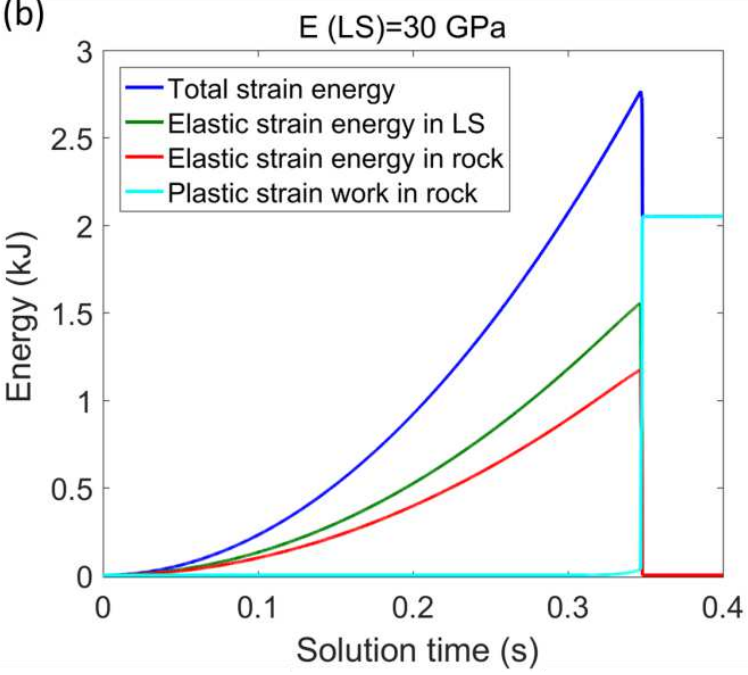

(d)

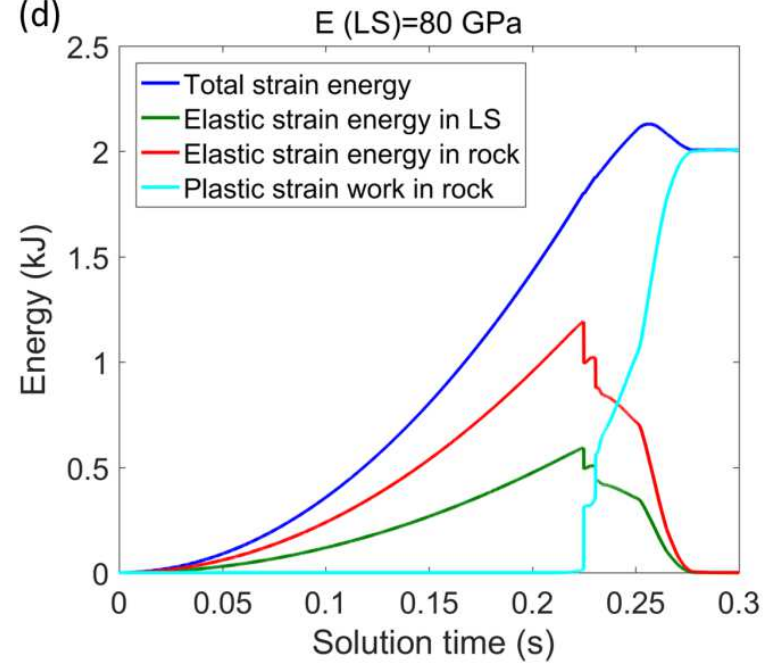

Fig. 4. Curves of energy components with solution time in the Tianhu granite under the loading system with different elastic modulus values.

To make a distinction between stable and unstable rock failures in UDEC, a rock failure can be identified as unstable failure when over $50 \%$ of elastic strain energy from its peak to residual value within a target rock is released instantaneously during the rock failure process. It should be noted that this criterion is aimed at providing a consistent objective basis to identify the rock failure modes in numerical models. However, the exact numerical threshold adopted was based solely on the author's judgement. This criterion of distinguishing stable and unstable rock failure with the change of elastic strain energy indicates that the rock failures under the loading system with elastic modulus values of $20 \mathrm{GPa}, 30 \mathrm{GPa}$ and $40 \mathrm{GPa}$ are unstable rock failures. For the cases of $80 \mathrm{GPa}$, the rapid and large change in elastic strain energy in the rock after peak value is less than $50 \%$, indicating this rock failure is stable rock failure. For all cases, the curves of total strain energy will always merge with curves of the plastic strain work when the rock loses all its strength, while elastic strain energy decreases to nearly zero once 
the rock specimen has lost its strength. It should be noted that the curve of "elastic strain energy in LS" is identical to that of "elastic strain energy in rock" for the case of $40 \mathrm{GPa}$.

The maximum elastic strain energy in the rock is the same for all the cases, but the maximum elastic strain energy in the loading system increases with the decreasing elastic modulus values of the loading system. The elastic strain energy in the rock specimen is also an energy source for rock failure, and it can be observed that the plastic strain work increase is larger than the elastic strain energy decrease in the rock for the cases of $20 \mathrm{GPa}$, $30 \mathrm{GPa}$ and $40 \mathrm{GPa}$ during rock failure. Further, the rapid decrease in total strain energy indicates that part of the elastic strain energy is dissipated into kinetic energy during the unstable rock failure process. Based the magnitude of plastic strain work increase and total strain energy decrease, we can conclude that the rock failure under the loading system with an elastic modulus of $20 \mathrm{GPa}$ has the largest intensity. These four compression tests indicate that the elastic strain energy in the loading system is a significant energy source for plastic strain work and kinetic energy during the rock failure process and a smaller LSS stores more elastic strain energy and is more likely to result in an unstable and violent rock failure.

\section{Influence of rock stiffness on rock failure modes}

When a constant velocity is applied directly on top of the steel platen (Fig. 1), it can be assumed that the UCS platform without the loading beam has an LSS of infinity, to exclude the influence of elastic strain energy within the loading system on rock failure modes. The effective rock stiffness is a function of Young's modulus and geometry of the rock, and the magnitude of rock stiffness can influence the amount of elastic strain energy stored in the rock specimen. While keeping the rock geometry constant, different Young's modulus values (20 $\mathrm{GPa}, 25 \mathrm{GPa}, 30 \mathrm{GPa}$, and $40 \mathrm{GPa}$ ) for the Tianhu granite specimen under a LSS of infinity were selected to present the different rock failure modes and evaluate the influence of rock stiffness on the rock failure modes.

\subsection{Stress-strain behavior of rock with different stiffness}

The axial stress-strain curves of the Tianhu granite specimen with different Young's modulus values are shown in Fig. 5a, where the LSS is infinity such that the elastic strain energy is only stored in the rock specimen itself. In this study, the axial strain represents the displacement closure between the two ends of the rock specimen divided by its length, which is a common method to obtain the axial strain in the laboratory. Although rock strength weakening without axial strain increase can be observed for the case of $30 \mathrm{GPa}$ and $40 \mathrm{GPa}$ in Fig. 5a, changes in strain tensors within the rock just cannot reflect the change of different strain tensors locally within part of the rock specimen. After the peak strength, the rock specimen having a smaller Young's modulus value tends to have a steeper slope of the stress-strain curve during its strength weakening process. 
(a)

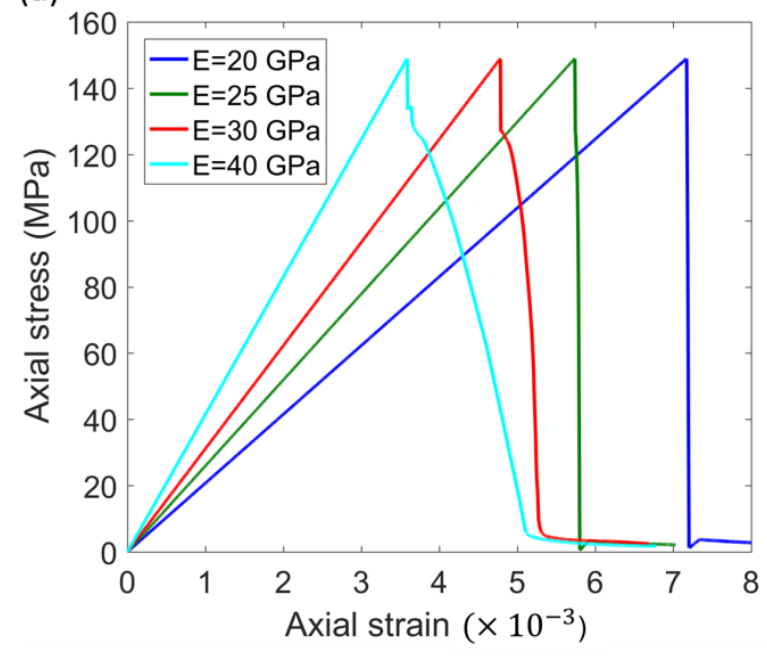

(b)

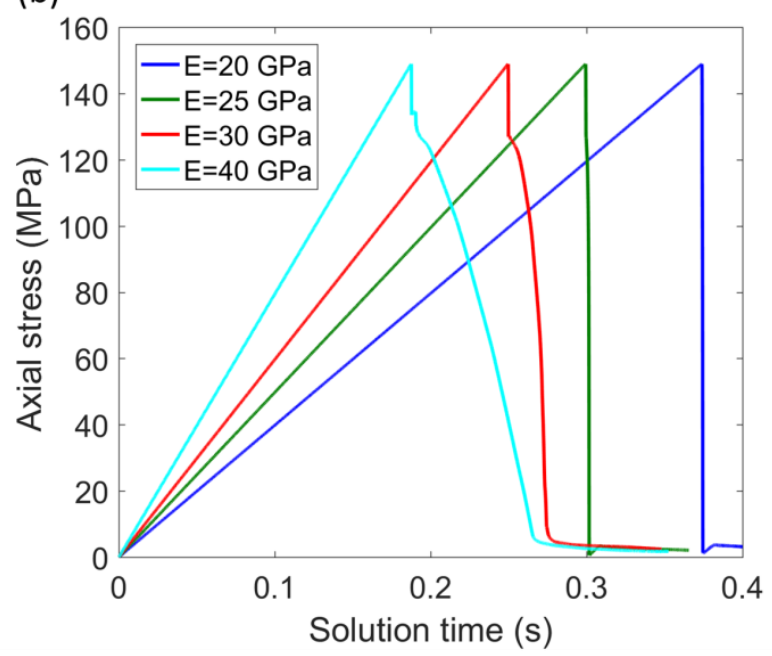

Fig. 5. Stress-strain curves of the Tianhu granite specimen with different Young's modulus values under LSS of infinity.

In Fig. 5b, the rapid decrease in axial stress from its maximum value to residual stress (near zero) can be clearly observed in the curves for modulus values of $20 \mathrm{GPa}, 25 \mathrm{GPa}$ and $30 \mathrm{GPa}$, suggesting these three failures are potential unstable rock failures. For the cases of $40 \mathrm{GPa}$, the gradual stress decrease from peak stress to the residual stress indicates stable rock failure, which could not have continued without the constant loading velocity on the upper boundary. Different amount of solution time for the rock specimen having different modulus values to reach the same peak strength results from the same constant boundary velocity but different rock stiffness.

\subsection{Energy transformations}

The rock stiffness, a function of rock geometry and Young's modulus, can affect the amount of stored elastic strain energy at rock peak strength. As shown in Fig. 6, the rock specimen with the modulus value of 20 GPa has the largest maximum elastic strain energy, while the maximum elastic strain energy is lowest for the case of $40 \mathrm{GPa}$. A large and rapid decrease in elastic strain energy can be observed for the rock with modulus values of $20 \mathrm{GPa}, 25 \mathrm{GPa}$ and $30 \mathrm{GPa}$, where the plastic strain work increases simultaneously during the same period. The rapid elastic strain energy decrease is about $0.5 \mathrm{~kJ}$, which is less than $50 \%$ of the elastic strain energy decrease from peak to residual values, indicating a stable rock failure for the case of $30 \mathrm{GPa}$. The rapid total strain energy decrease during these two failures indicates that part of the elastic strain energy within the rock is dissipated into kinetic energy. Given that no large and rapid change of elastic strain energy and plastic strain work can be observed for the rock specimen with the modulus value of $40 \mathrm{GPa}$, this rock failure can be classified as stable rock failure. 

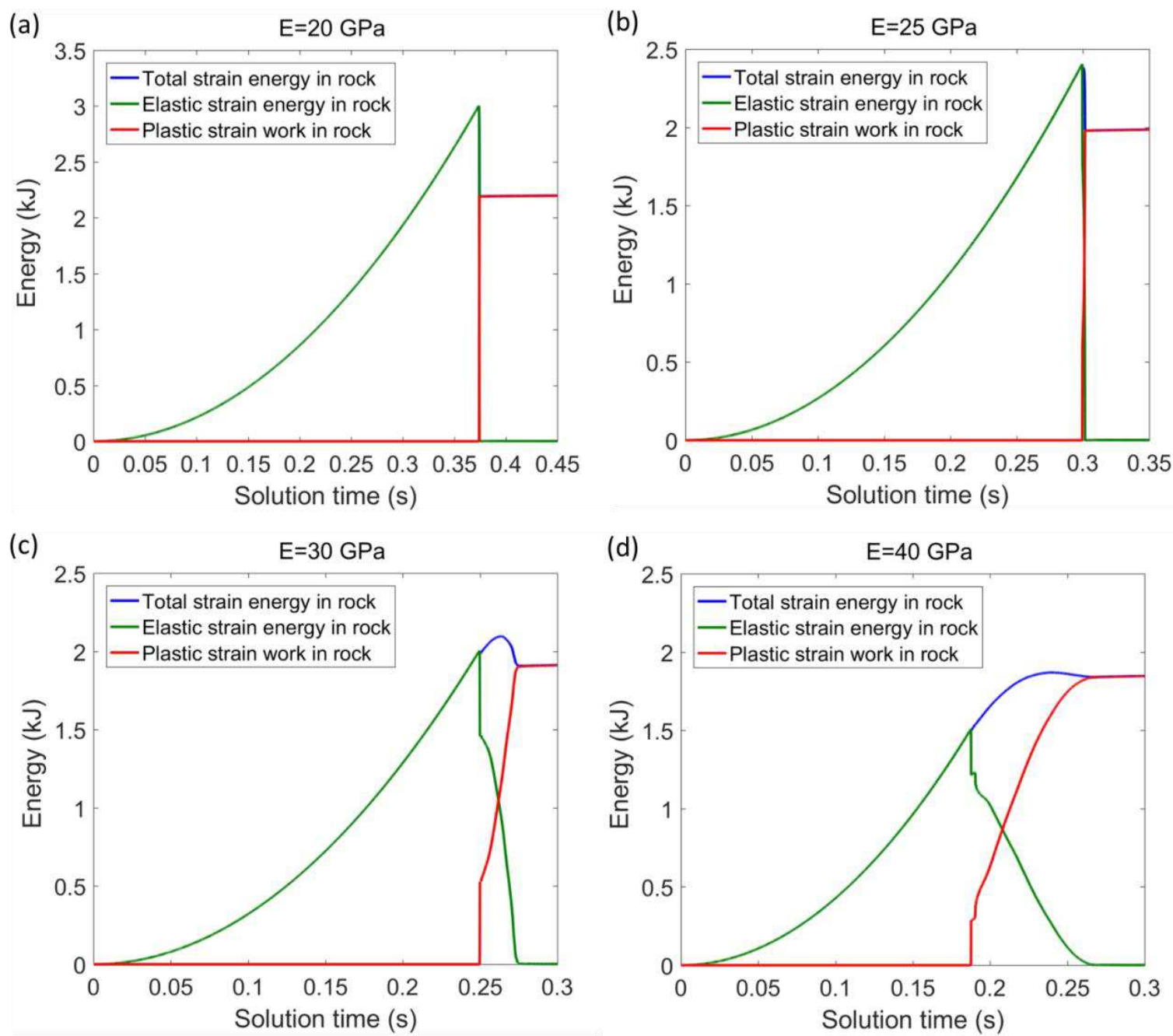

Fig. 6 Curves of energy components with solution time in the Tianhu granite specimen for different values of Young's modulus with an LSS of infinity.

As Young's modulus increases from $20 \mathrm{GPa}$ to $40 \mathrm{GPa}$, the maximum elastic strain energy decreases from $3.0 \mathrm{~kJ}$ to $1.5 \mathrm{~kJ}$, while unstable rock failures are only observed in rock with Young's modulus of $20 \mathrm{GPa}$ and $25 \mathrm{GPa}$. Larger changes of elastic strain energy, plastic strain work and total strain energy (or damped kinetic energy) can be observed during the rapid rock failure process in the $20 \mathrm{GPa}$ case than in the $25 \mathrm{GPa}$ case, which implies that the rapid changes in these energy components during unstable rock failure also can be used as indicators of rock failure intensity. A rock having a smaller stiffness tends to store a larger amount of elastic strain energy at the same rock peak strength, and the stored elastic strain energy in the rock also can greatly influence the rock failure modes. 


\section{Influence of rock brittleness on rock failure modes}

Rock brittleness can be understood as a rock's ability to resist loading, with increasing deformation during its failure process, which is not an inherent material property. In geotechnical engineering, the slope of the post-peak stress-strain curve can be used as a brittleness index, and this can be controlled by the strain-softening parameters used in numerical models. Taking the Tianhu granite as a baseline, another hypothetical set of strainsoftening parameters is tested to promote a larger rock brittleness or steeper slope of the post-peak stress-strain curve in the Tianhu granite, and this case is referred to as Brittle Tianhu granite in this study.

\subsection{Physical behaviors rock with different brittleness}

Cohesion-weakening parameters of the strain-softening model for the Brittle Tianhu granite specimen are listed in Table 3, while the rest rock parameters are the same as those of the Tianhu granite specimen as shown in Table 1. The only difference between these two rock specimens is the strain-softening behavior of the rock, as represented by the parameters in Table 2 and Table 3, respectively. By comparing the rock failure behaviors of the Tianhu granite and Brittle Tianhu granite, the influence of rock brittleness on rock failure modes can be analyzed. To exclude the influence of the elastic strain energy within the loading system, the Tianhu granite specimen and Brittle Tianhu granite specimen are loaded to failure under a LSS of infinity.

Table 3 Cohesion-weakening parameters of the strain-softening model for the Brittle Tianhu granite specimen.

\begin{tabular}{cc}
\hline Plastic shear strain & $\begin{array}{c}\text { Cohesion yield stress } \\
(\mathrm{MPa})\end{array}$ \\
\hline 0 & 37.5 \\
0.0005 & 37 \\
0.01 & 32.5 \\
0.03 & 25 \\
0.05 & 15 \\
0.08 & 0.1 \\
\hline
\end{tabular}

Under LSS of infinity, the axial stress-strain curves of the Tianhu granite and Brittle Tianhu granite are shown in Fig. 7. The axial stress follows the same path from $0 \mathrm{MPa}$ to $150 \mathrm{MPa}$ with the increase in axial strain in both rocks. After the peak stress, the axial stress in Tianhu granite decreases slowly and gradually with the increase in axial strain, while a rapid stress decrease in Tianhu granite occurs with no perceptible increase in axial strain, is obtained by dividing the displacement closure between the two ends of the rock specimen by its length. 
In summary, the brittle Tianhu granite is clearly more brittle than the Tianhu granite, based on the slope of the post-peak stress-strain curves.

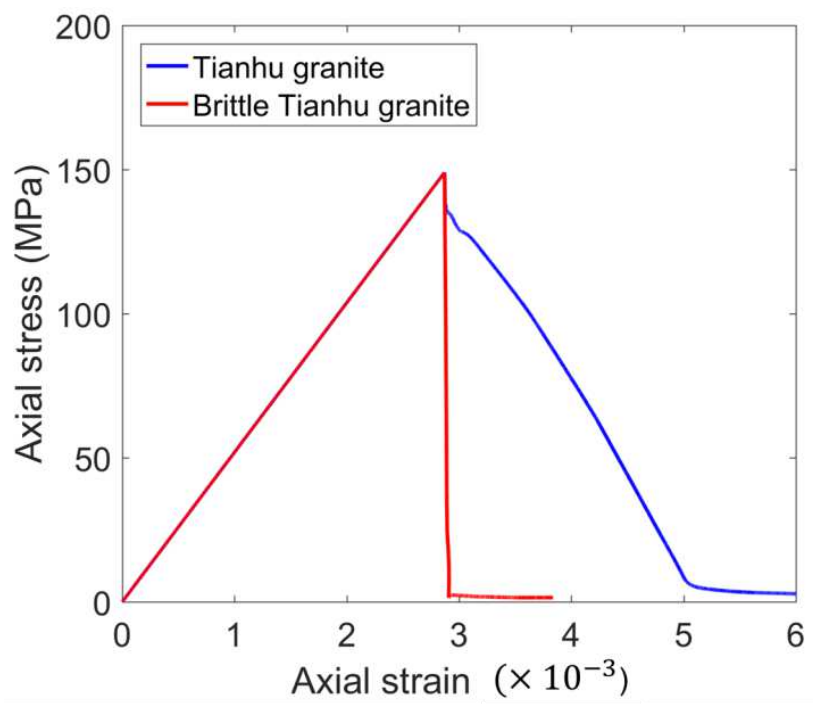

Fig. 7. Stress-strain and stress-time curves of the Tianhu granite and brittle Tianhu granite under LSS of infinity.

\subsection{Energy transformations}

The elastic strain energy in the rock is the only stored energy source of dynamic rock failure during a very short timeframe under LSS of infinity, since gravitational energy is not considered in this study. In Fig. 8, both rock specimens have the same maximum elastic strain energy of $1.2 \mathrm{~kJ}$ at the peak strength, when the plastic strain work is close to zero. After the peak point, the elastic strain energy gradually decreases to zero and plastic strain work slowly increases to its maximum value for the Tianhu granite specimen, showing that its failure develops and progresses with solution time. The total strain energy, as the sum of elastic strain energy and plastic strain work in the rock, increases until the residual state of the Tianhu granite specimen is achieved, representing no perceptible released kinetic energy during this rock failure. However, the Brittle Tianhu granite specimen has a rapid decrease in elastic strain energy and increase in plastic strain work immediately after the rock peak strength, resulting from the dissipation of kinetic energy. The changes of these three energy components with solution time indicate that the Tianhu granite failure is a stable rock failure, while the Brittle Tianhu granite failed in an unstable manner. 
(a)

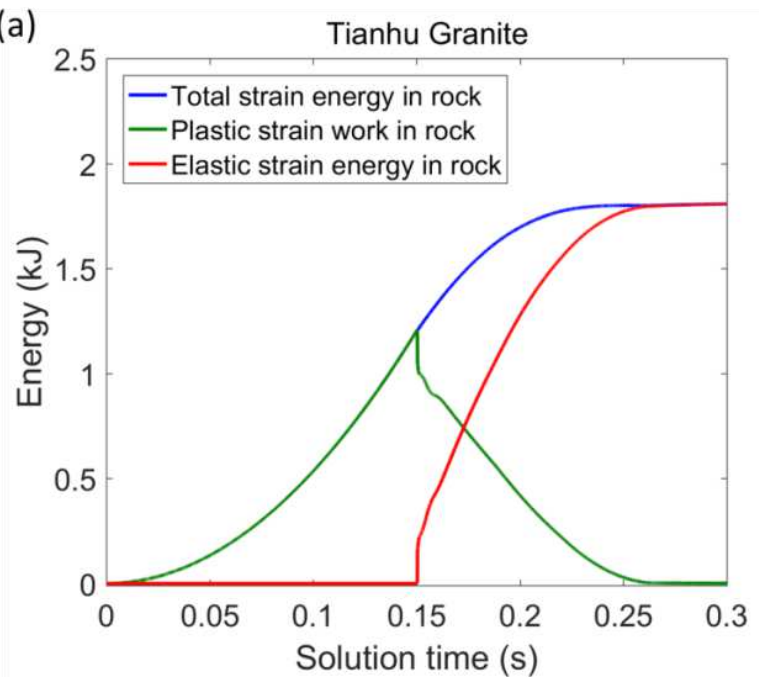

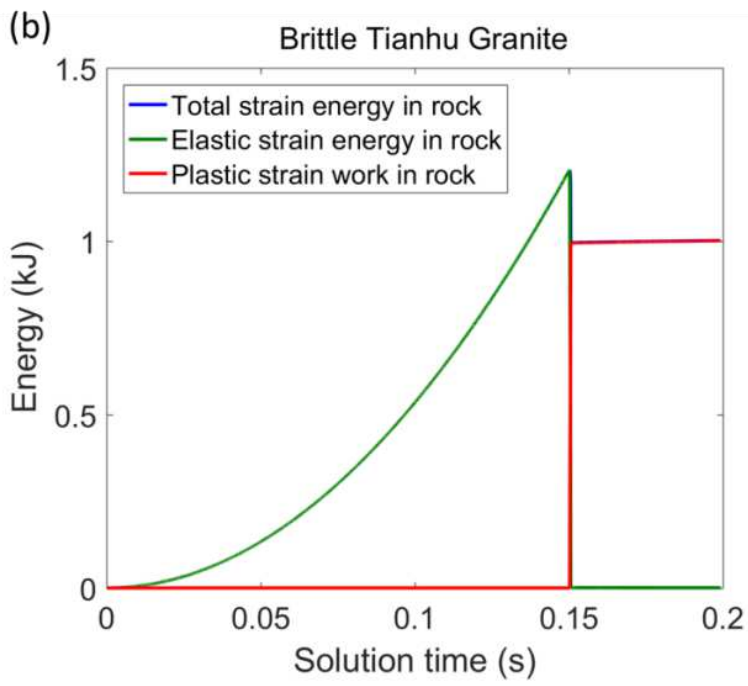

Fig. 8. Curves of energy components with solution time in the Tianhu granite and Brittle Tianhu granite specimens under LSS of infinity.

Although both rock specimens have elastic strain energy of $1.2 \mathrm{~kJ}$ at the same peak strength, their brittleness, affected by the strain-softening parameters, results in different rock failure modes due to the amount of plastic strain work for the residual state of the rocks. The plastic strain work at residual state is $1.8 \mathrm{~kJ}$ for the Tianhu granite and $1.0 \mathrm{~kJ}$ for the Brittle Tianhu granite. Clearly, the elastic strain energy is larger than the plastic strain work after residual state for the Brittle Tianhu granite, while elastic strain energy at rock peak strength is smaller than the magnitude of plastic strain work at residual state for the Tianhu granite. For unstable rock failure to occur, the elastic strain energy should be able to supply enough energy to induce the rock failure spontaneously. The relatively magnitudes of available elastic strain energy before rock failure and plastic strain work at residual state determines the Tianhu granite failure has to be a stable rock failure, while the Brittle Tianhu granite can be an unstable rock failure. Therefore, brittle rock tends to fail violently, for it produces less amount of plastic strain work for the residual state of rock.

\section{Discussions of numerical results using graphical and numerical methods}

The fundamental theory of unstable rock failure considers the LSS and post-peak rock stiffness, whose relative magnitudes were thought to determine the rock failure modes (Cook 1965; Salamon 1970a; Manouchehrian and Cai 2015; Xu and Cai 2017). The post-peak rock stiffness can be represented by the slope of the post-peak stress-strain curves of the rock during its strain-weakening process (Fig. 9). After the peak stress of a loading test, the rock begins its strain weakening stage while the loading system goes to the unloading stage. In Fig. 9, the enclosed area between the curves of soft loading system and post-peak behavior of rock is thought to be the amount of released kinetic energy during unstable rock failure (Cook 1965; Salamon 1970a, 1984; Rice 1983). 


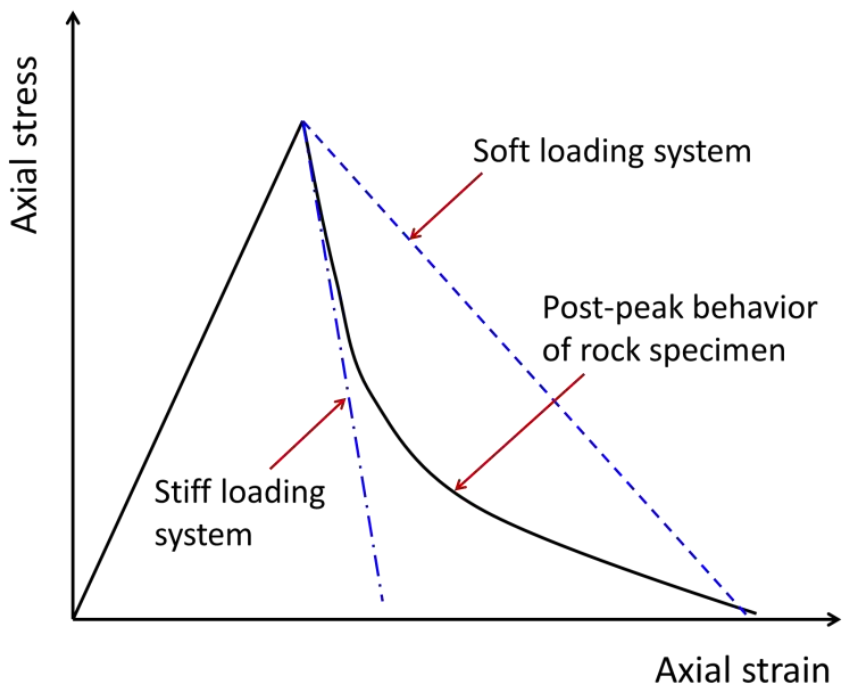

Fig. 9 Schematic representation of the physical explanation of stable failure and unstable failure (after Cook, 1965).

Based on Cook (1965), the enclosed area between the curves of post-peak behavior of a rock and an infinitely stiff loading system should always be zero, which also means unstable rock failure cannot occur in a rock specimen under LSS of infinity. However, unstable rock failures are observed in Brittle Tianhu granite specimen under LSS of infinity and Tianhu granite specimen with Young's modulus of $20 \mathrm{GPa}$ and $25 \mathrm{GPa}$ under LSS of infinity in this study. The numerical results seem to contradict the fundamental theory of unstable rock failure which is theoretically based on the relative magnitude between post-peak stiffness of rock and the LSS. However, the unstable rock failure theory proposed by Cook (1965) was based on the theoretical assumption that the rock specimen would have the isotropic elastic and plastic strain within the entire rock. In the laboratory, it is not practical to measure the average axial strain values within every zone of a rock specimen. The commonly used axial strain, equivalent to the shortening distance of the rock specimen divided by its length, is not always able to reflect the change of axial strain within the rock specimen. Strain gauges can measure the axial strain on a specimen well before rock failure, but its measurement is localized on the surface of rock specimen.

The average axial strain by zone can be obtained by accessing to axial strain values in each zone of the rock specimen model in UDEC. During the strength-weakening process, elastic strain in some zones begins to decrease while large plastic strain increase will be observed in some localized zones of the rock. The decrease in average axial strain would be observed after the peak strength if the decrease in average elastic strain was larger than the increase in average plastic strain within the entire rock, while the axial strain obtained with rock specimen shortening divided by rock length cannot decrease with the constant loading velocity from the boundary. After the initiation of plastic strain in rock specimen with Mohr-Coulomb material, the axial strain by zone $\left(\Delta \mathrm{e}_{\mathrm{y}-}\right.$ zone) equals to the sum of elastic strain $\left(\Delta e_{y}^{e}\right)$ and plastic strain in Eq. (10). The plastic strain is two time the 
product between a constant value $(\lambda)$ and average strain by displacement $\left(\Delta \mathrm{e}_{\mathrm{y}-\mathrm{disp}}\right)$, which is the shortening distance of the rock specimen divided by its length (Itasca Consulting Group 2014).

$$
\Delta e_{y-z o n e}=\Delta e_{y}^{e}+2 \lambda * \Delta e_{y-d i s p}
$$

Based on Eq. (10), the elastic strain will decrease, and plastic strain will increase during the rock strength weakening stage in Mohr-Coulomb model, which also means the axial strain by zone is different from the average strain by displacement. When the elastic strain decreases faster than the increase in plastic strain, the axial strain by zone will decrease with solution time, indicating the rock strength-weakening will be spontaneous at that moment. Under LSS of infinity and using the average axial strain in each zone, the curves of average stress-strain in the Tianhu granite specimen with Young's modulus values of $20 \mathrm{GPa}, 25 \mathrm{GPa}, 30 \mathrm{GPa}$, and $40 \mathrm{GPa}$ are also obtained and plotted in Fig. 10.

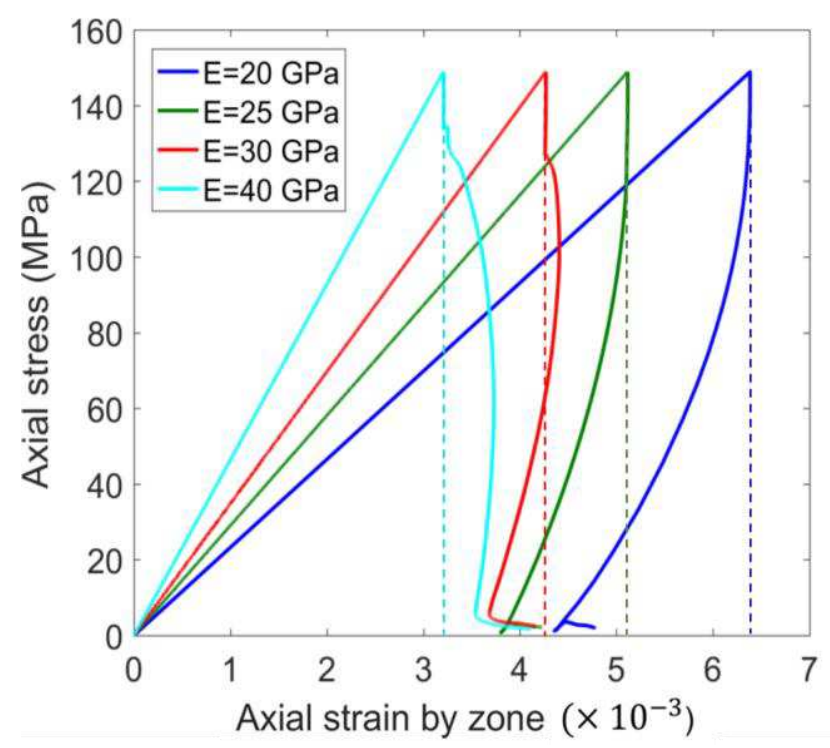

Fig. 10 The curves of average stress-strain by zone in the Tianhu granite specimen with Young's modulus values of $20 \mathrm{GPa}, 25 \mathrm{GPa}, 30 \mathrm{GPa}$ and $40 \mathrm{GPa}$.

With infinite LSS, the curve of the loading system is a vertical (dash) line passing through the peak point in each curve in Fig. 10, so the failures of the rock specimens having Young's modulus of $20 \mathrm{GPa}$ and $25 \mathrm{GPa}$ correspond to unstable rock failures. Some area to the left of vertical line passing through the peak point exists for the case of $30 \mathrm{GPa}$, but its failure modes cannot be observed directly from Fig. 10. Stable rock failure can be observed directly for the case of $40 \mathrm{GPa}$. Just from the average stress-strain curve of the $30 \mathrm{GPa}$ case, the rock failure modes for the case of $30 \mathrm{GPa}$ cannot be classified directly from the curves. Under LSS of infinity, negative post-peak rock stiffness indicates unstable rock failure while positive post-peak rock stiffness represents stable rock failure. If the curve of loading system intersects with the post-peak stress-strain curve, a second criterion is required to identify the rock failure modes. In Fig. 11, the average stress-strain curves of the Tianhu granite and 
Brittle Tianhu granite under LSS of infinity also follows the above characteristics, and the vertical dash line represent the infinitely stiff loading system.

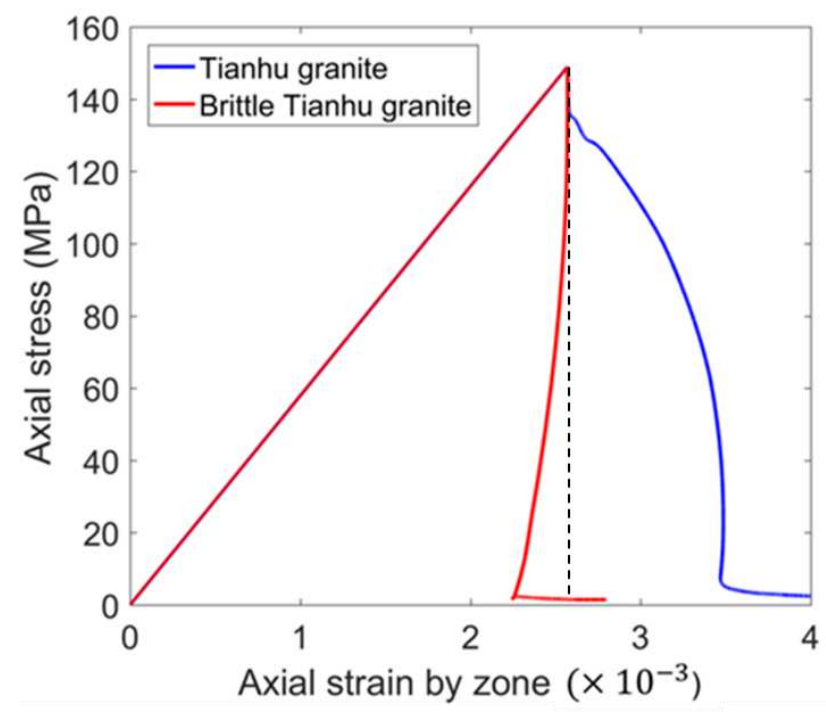

Fig. 11 The curves of average stress-strain by zone in the Tianhu granite and Brittle Tianhu granite under LSS of infinity.

The relative magnitude between post-peak rock stiffness and LSS will determine whether or not the stored elastic strain energy in the loading system can be spontaneously transferred into the rock specimen and result in unstable rock failure. As shown in Fig. 10 and Fig. 11, the post-peak rock stiffness is not a constant value, even if the model geometry is simple. When the LSS is not infinity, the post-peak rock stiffness must consider the geometry and elastic modulus of the loading system. The geometry of loading system and the rock specimen is different in this study, the comparison between the magnitudes of LSS and post-peak rock stiffness of the Tianhu granite rock specimen is not discussed.

Compared with the graphical or theoretical method, the numerical approach developed is able to study unstable rock failure in different model geometries (e.g. fault-slip around a circular excavation). Moreover, the distributions of various energy components such as plastic strain work density within each zone of a large model can also be obtained to benefit our understanding of the underlying energy mechanisms.

\section{Conclusions}

The equations of different energy components, including the elastic strain energy, plastic strain work and total strain energy, were integrated into the UDEC software in this study. This new energy approach was demonstrated to be capable of tracking the energy transformations between different energy components during rock failure in numerical models, independent of the geometry and complexity of the models. It was found that 
the rapid stress decrease immediately following the attainment of peak strength can be used as an indicator of potential unstable rock failure in UCS tests. In addition, rapid and large changes in total strain energy, elastic strain energy and plastic strain work during rock failure could be utilized as indicators of unstable rock failure, and the magnitudes of these rapid changes could also represent the unstable rock failure intensity. Unstable failure is based on the criterion that more than $50 \%$ of elastic strain energy from its peak to residual value within a target rock should be released instantaneously during the rock failure process. The occurrence of unstable rock failure depends on the available elastic strain energy for plastic strain work during rock failure, while the damped kinetic energy results from the difference between the available elastic strain energy and the induced plastic strain work.

Unstable rock failure tends to occur in a rock with large brittleness and small stiffness under a soft loading system. The elastic strain energy within the entire system is the energy source of plastic strain work and released kinetic energy during unstable rock failure, and it plays a significant role in governing rock failure modes. A larger potential for unstable rock failure in a system with smaller LSS and rock stiffness can be attributed to the fact that the magnitude of elastic strain energy in the entire model at rock peak strength increases with decreasing rock stiffness and LSS. It also shows that brittle rock requires less elastic strain energy for plastic strain work than ductile rock during the rock failure when other parameters such as rock stiffness and LSS are held constant.

Both graphical and numerical methods can be used to identify the rock failure modes and calculate the released kinetic energy in a UCS test. It is also found that the fundamental theory of unstable rock failure by Cook (1965) and Salamon (1970) is based on the assumption that the rock has the same elastic and plastic strain values within each zone of the entire rock during its strength-weakening process. The energy-based approach in numerical models is independent of model geometries, and can thus provide much more details about different energy components during the rock failure process, providing a unique strength relative to analytical methods.

\section{Acknowledgments}

The authors wish to acknowledge research funding support from the CDC-NIOSH under Contract No. 200-201690154, in the Office of Mine Safety and Health Research program. We also thank Dr. Gabriel Walton at Colorado School of Mines for helpful discussions and suggestions.

\section{References:}

Andrianopoulos NP, Manolopoulos VM. Elastic strain energy density decomposition in failure of ductile materials under combined torsion-tension. Int J Mech Mater Eng. 2014;9(1):1-12.

Beck DA, Brady BHG. Evaluation and application and controlling parameters for seismic events in hard-rock mines. Int J Rock Mech Min Sci. 2002;39(5):633-42. 
Board M, Rorke T, Williams G, Gay N. Fluid injection for rockburst control in deep mining. Int J Rock Mech Min Sci Geomech Abstr. 2006;30(1):A68.

Chen G, He M, Fan F. Rock burst analysis using DDA numerical simulation. Int J Geomech. 2018;18(3):1-12.

Chen Z, He C, Wu D, Xu G, Yang W. Fracture evolution and energy mechanism of deep-buried carbonaceous slate. Acta Geotech. 2017;12(6):1243-60.

Cook NGW. A note on rockbursts considered as a problem of stability. J South African Inst Min Metall. 1965;(65):437-46.

Fakhimi A, Hosseini O, Theodore R. Physical and numerical study of strain burst of mine pillars. Comput Geotech. 2016;74:36-44. http://dx.doi.org/10.1016/j.compgeo.2015.12.018

Gong QM, Yin LJ, Wu SY, Zhao J, Ting Y. Rock burst and slabbing failure and its in fl uence on TBM excavation at headrace tunnels in Jinping II hydropower station. 2012;124:98-108.

Gu R, Ozbay U. Distinct element analysis of unstable shear failure of rock discontinuities in underground mining conditions. Int J Rock Mech Min Sci. 2014;68:44-54.

Gu R, Ozbay U. Numerical investigation of unstable rock failure in underground mining condition. Comput Geotech. 2015;63:171-82.

Hajiabdolmajid V, Kaiser P. Brittleness of rock and stability assessment in hard rock tunneling. Tunn Undergr Sp Technol. 2002;18(1):35-48.

He BG, Zelig R, Hatzor YH, Feng XT. Rockburst generation in discontinuous rock masses. Rock Mech Rock Eng. 2016a;49(10):4103-24.

He BG, Zelig R, Hatzor YH, Feng XT. Rockburst Generation in Discontinuous Rock Masses. Rock Mech Rock Eng. 2016b;49(10):4103-24.

He MC, Miao JL, Feng JL. Rock burst process of limestone and its acoustic emission characteristics under truetriaxial unloading conditions. Int J Rock Mech Min Sci. 2010;47(2):286-98. http://dx.doi.org/10.1016/j.ijrmms.2009.09.003

He MC, Nie W, Zhao ZY, Guo W. Experimental investigation of bedding plane orientation on the rockburst behavior of sandstone. Rock Mech Rock Eng. 2012;45(3):311-26.

Heinze T, Galvan B, Miller SA. A new method to estimate location and slip of simulated rock failure events. Tectonophysics. 2015;651:35-43. http://dx.doi.org/10.1016/j.tecto.2015.03.009

Itasca Consulting Group I. UDEC 6.0, Energy Calculation. Mannual. 2014;1-28.

Jaeger, J. C.; Cook, N. G. W.;Zimmerman RW. Fundamentals of Rock Mechanics. 4th Editio. 2007.

Kaiser PK, Cai M. Design of rock support system under rockburst condition. J Rock Mech Geotech Eng. 2012;4(3):215-27. http://dx.doi.org/10.3724/SP.J.1235.2012.00215

Khademian Z, Ozbay U. Computational framework for simulating rock burst in shear and compression. Int J Rock Mech Min Sci. 2018;110(September):279-90. https://doi.org/10.1016/j.ijrmms.2018.06.022 
Kias E, Ozbay U. Modeling unstable failure of coal pillars in underground mining using the discrete element method. 47th US Rock Mech Symp. 2013;

Kim BH, Larson MK. Evaluation of bumps-prone potential regarding the spatial characteristics of cleat in coal pillars under highly stressed ground conditions. 2017;17-0370.

Leveille P, Sepehri M, Apel DB. Rockbursting potential of Kimberlite: a case study of Diavik Diamond Mine. Rock Mech Rock Eng. 2017.

Levkovitch V, Beck D, Reusch F. Numerical Simulation of the Released Energy in Strain-softening rock materiales and its application in Estimating Seismic hazards in Mines. Eighth Int Symp Rockburst Seism Mines. 2013;1-7.

Manouchehrian A, Cai M. Simulation of unstable rock failure under unloading conditions. Can Geotech J. 2015;13(June):1-13.

Poeck EC. Analyzing the Potential for Unstable Mine Failures. Colorado School of Mines; 2017.

Rice JR. Constitutive Relations for Fault Slip and Earthquake Instabilities. 1983;121(3).

Sainoki A, Mitri HS. Dynamic behaviour of mining-induced fault slip. Int J Rock Mech Min Sci. 2014;66:19-29. http://dx.doi.org/10.1016/j.ijrmms.2013.12.003

Sainoki A, Mitri HS. Back analysis of fault-slip in burst prone environment. J Appl Geophys. 2016;134:159-71. http://dx.doi.org/10.1016/j.jappgeo.2016.09.009

Salamon MDG. Stability, instability and design of pillar workings. Int J Rock Mech Min Sci. 1970a;7(6):613-31.

Salamon MDG. Stability, instability and design of pillar workings. Int J Rock Mech Min Sci. 1970b;7(6):613-31.

Salamon MDG. Energy considerations in rock mechanics: fundamental results. J South African Inst Min Metall. 1984;84(8):233-46.

Salamon MDG, Badr S, Mendoza R, Ozbay MU. Pillar failure in deep coal seams: numerical simulation. South African Inst Min Metall. 2003;1011-8.

Singh SP. The influence of rock properties on the occurrence and control of rockbursts. Min Sci Technol. 1987;5(1):11-8.

Singh SP. Burst energy release index. Rock Mech Rock Eng. 1988;21(2):149-55.

Su G, Jiang J, Zhai S, Zhang G. Influence of tunnel axis stress on strainburst: an experimental study. Rock Mech Rock Eng. 2017;50(6):1551-67.

Vazaios I, Diederichs MS, Vlachopoulos N. Assessment of strain bursting in deep tunnelling by using the fi nitediscrete element method. J Rock Mech Geotech Eng. 2019;11(1):12-37. https://doi.org/10.1016/j.jrmge.2018.06.007

Walton G, Diederichs MS. A new model for the dilation of brittle rocks based on laboratory compression test data with separate treatment of dilatancy mobilization and decay. Geotech Geol Eng. 2015;33(3):661-79. http://dx.doi.org/10.1007/s10706-015-9849-9 
Wang F, Kaunda R. Assessment of rockburst hazard by quantifying the consequence with plastic strain work and released energy in numerical models. Int J Min Sci Technol. 2019;29(1):93-7.

Wawersik WR, Fairhurst C. A study of brittle rock fracture in laboratory compression experiments. Int J Rock Mech Min Sci. 1970;7(5):561-75.

Whyatt, J, W. Blake TW. 60 years of rockbursting in the Coeur D'alene district of northern Idaho, USA: lessons learned adn remaining issues. 2002;

$\mathrm{Xu}$ YH, Cai M. Influence of loading system stiffness on post-peak stress-strain curve of stable rock failures. Rock Mech Rock Eng. 2017;1-21.

Zhang D, Ranjith PG, Perera MSA. The brittleness indices used in rock mechanics and their application in shale hydraulic fracturing: A review. J Pet Sci Eng. 2016;143:158-70. http://dx.doi.org/10.1016/j.petrol.2016.02.011

Zhao XG, Cai M. Influence of specimen height-to-width ratio on the strainburst characteristics of Tianhu granite under true-triaxial unloading conditions. Can Geotech J. 2014;52(7):890-902. http://www.nrcresearchpress.com/doi/10.1139/cgj-2014-0355

Zhu WC, Li ZH, Zhu L, Tang CA. Numerical simulation on rockburst of underground opening triggered by $\begin{array}{lllll}\text { dynamic } & \text { disturbance. } & \text { Tunn } & \text { Undergr 2010;25(5):587-99. }\end{array}$ http://dx.doi.org/10.1016/j.tust.2010.04.004

Zubelewicz A, Mróz Z. Numerical simulation of rock burst processes treated as problems of dynamic instability. Rock Mech Rock Eng. 1983;16(4):253-74. 


\section{Figures}

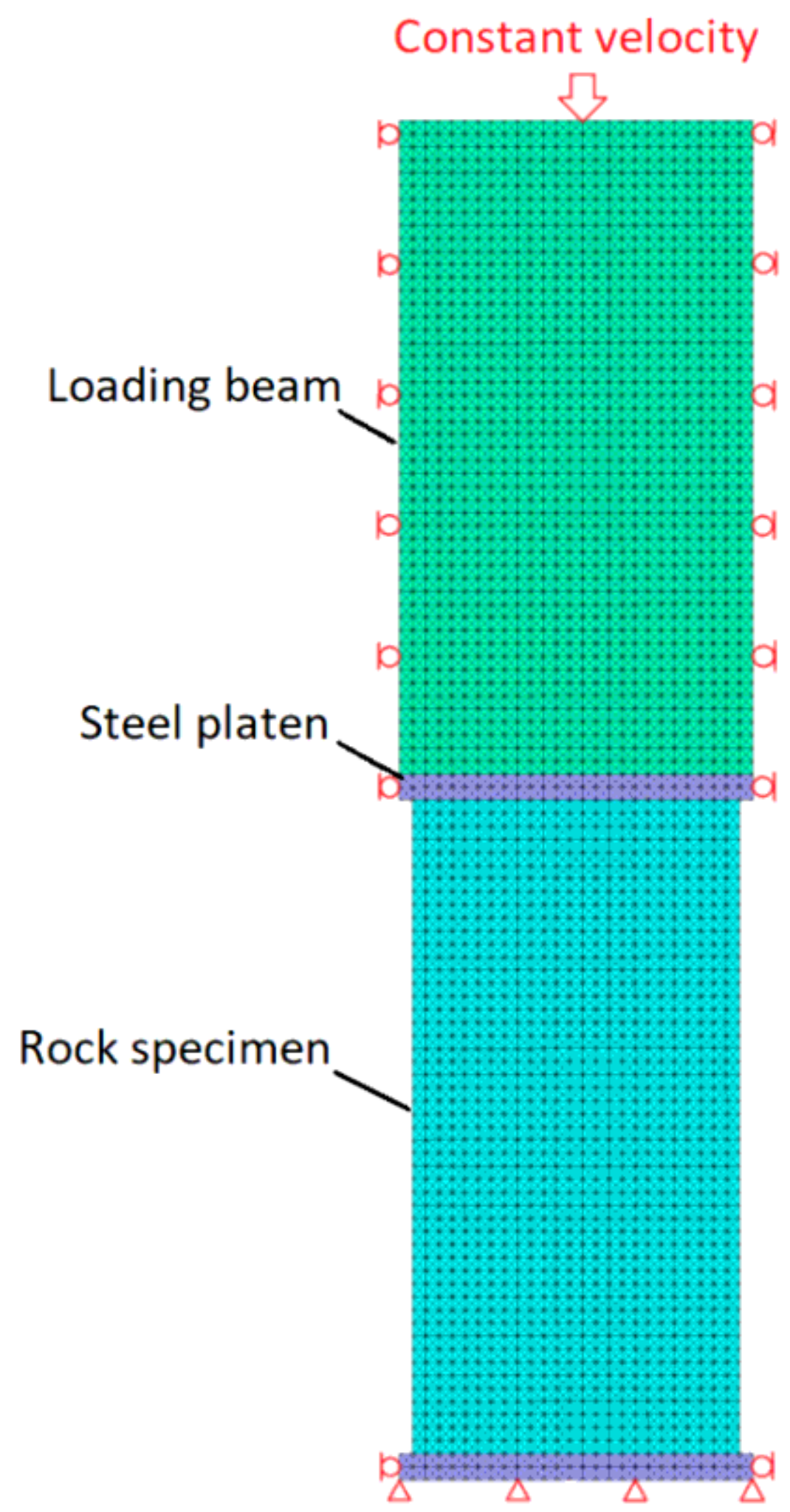

Figure 1

Geometry, mesh and boundary conditions of the simplified UCS test platform in UDEC. 


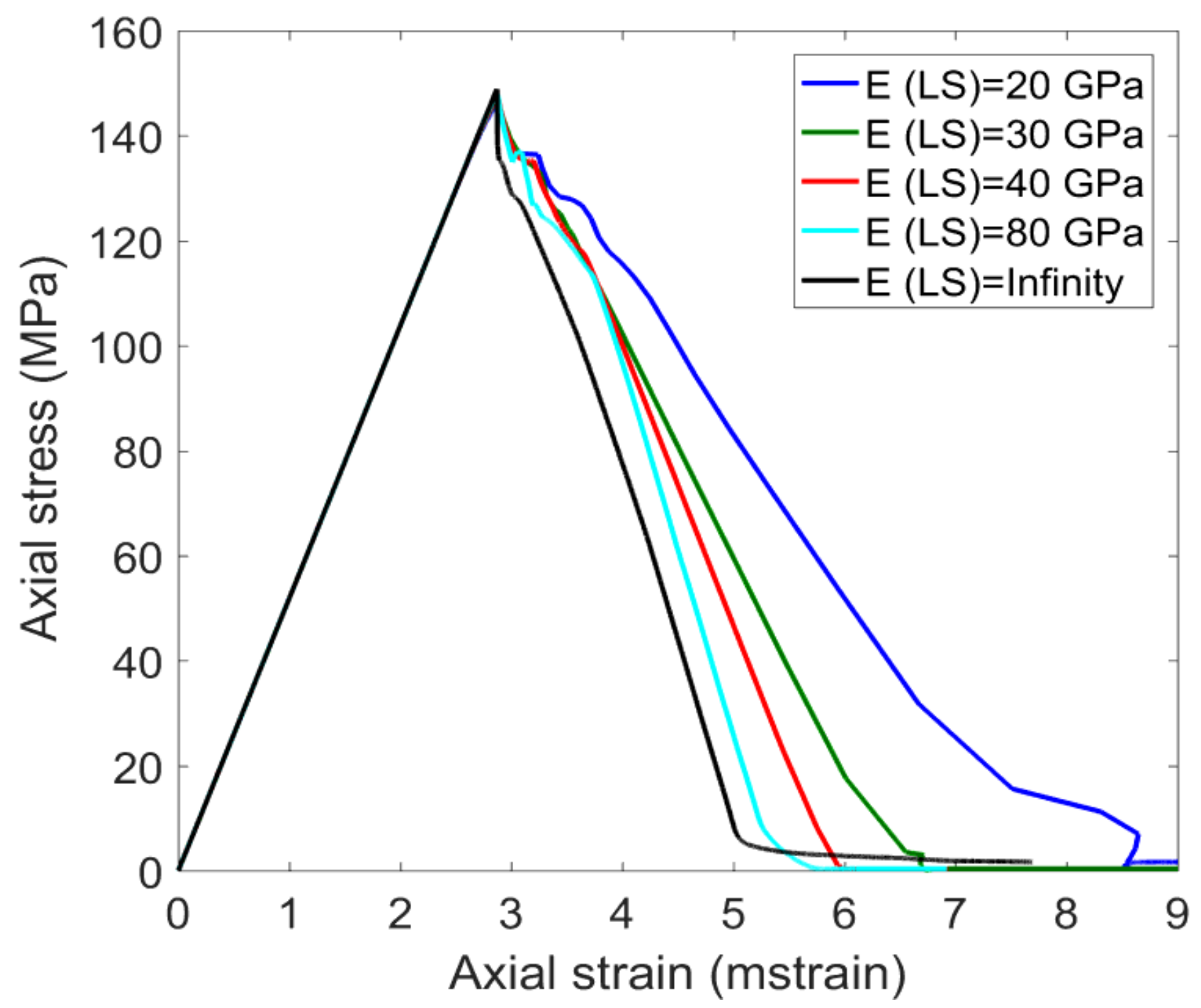

Figure 2

Stress-strain curves of the Tianhu granite specimen under the loading system with different elastic modulus values. 
(a)

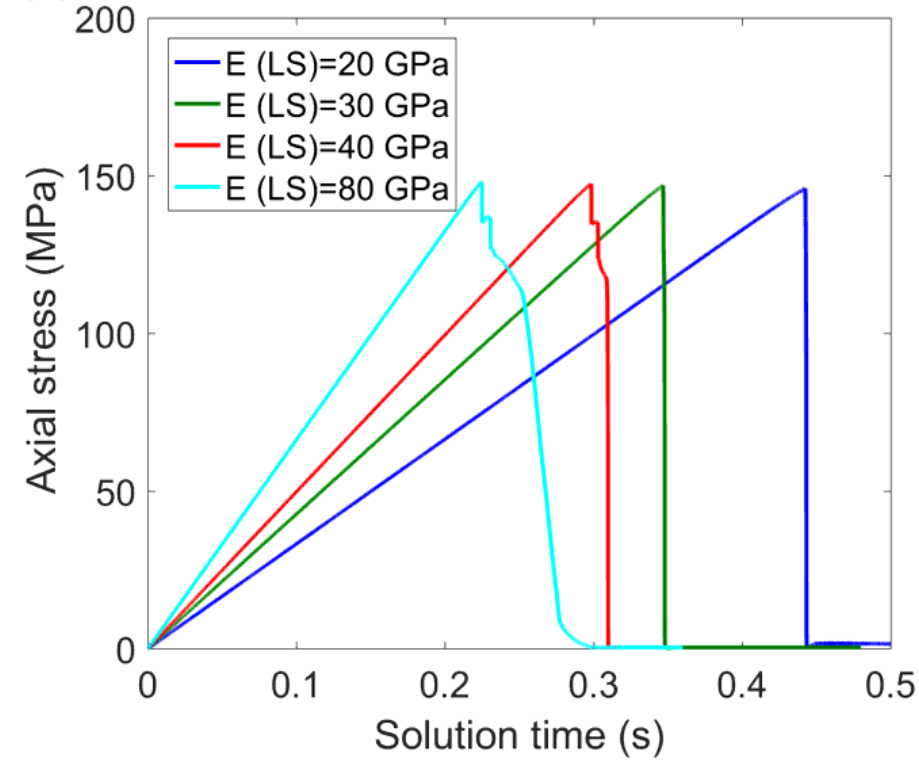

(b)

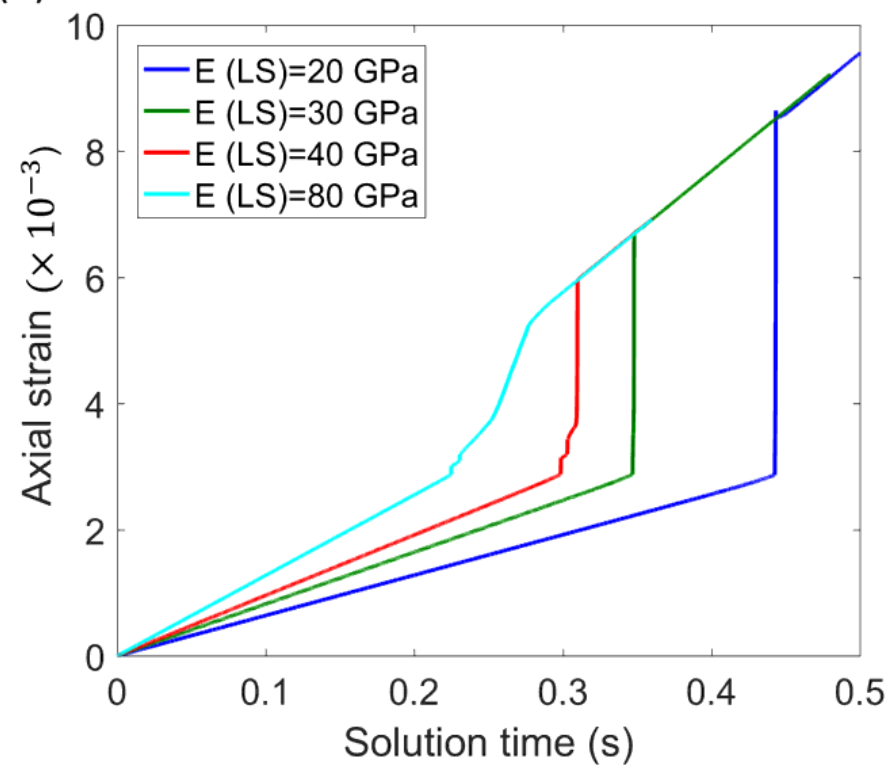

\section{Figure 3}

Stress-strain and stress-time curves of the Tianhu granite specimen under the loading system with different elastic modulus values. 
(a)

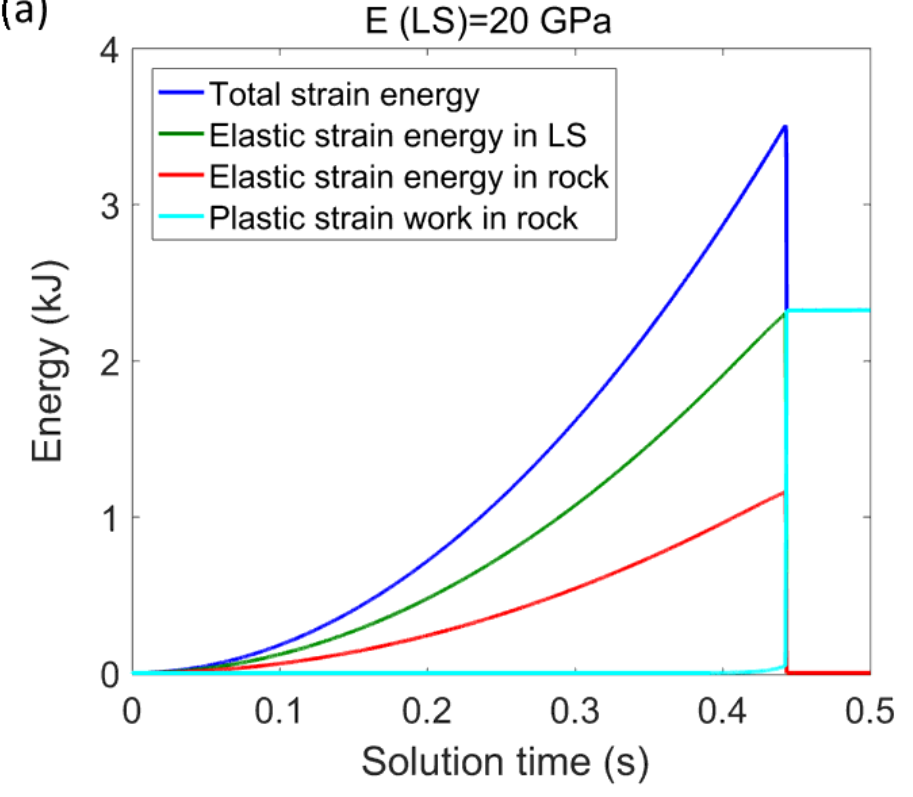

(c)

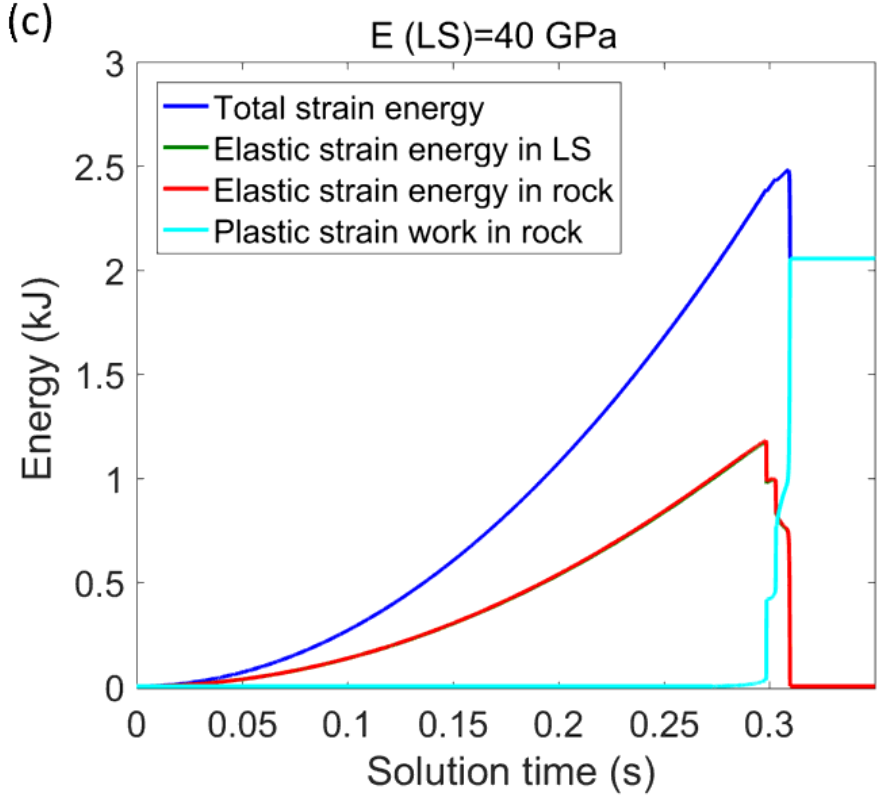

(b)

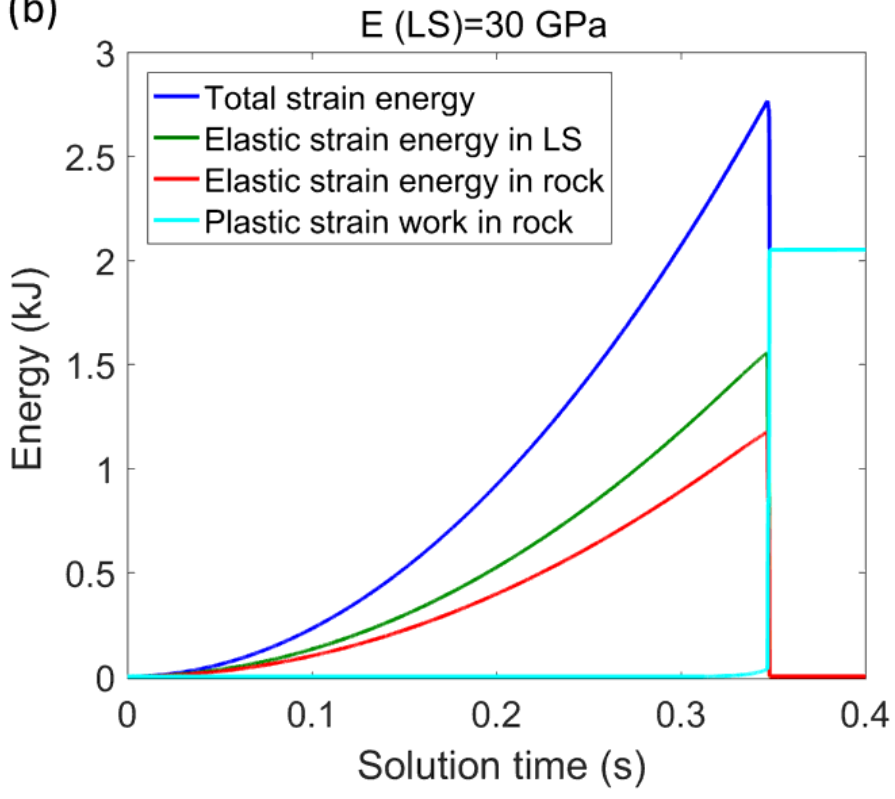

(d)

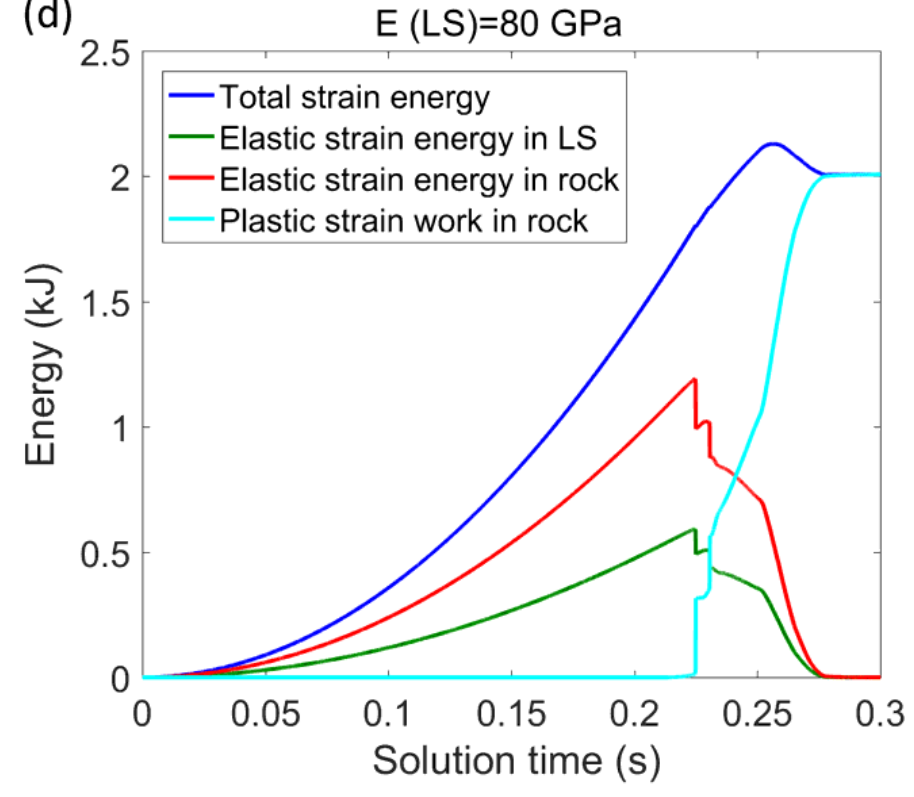

Figure 4

Curves of energy components with solution time in the Tianhu granite under the loading system with different elastic modulus values. 
(a)

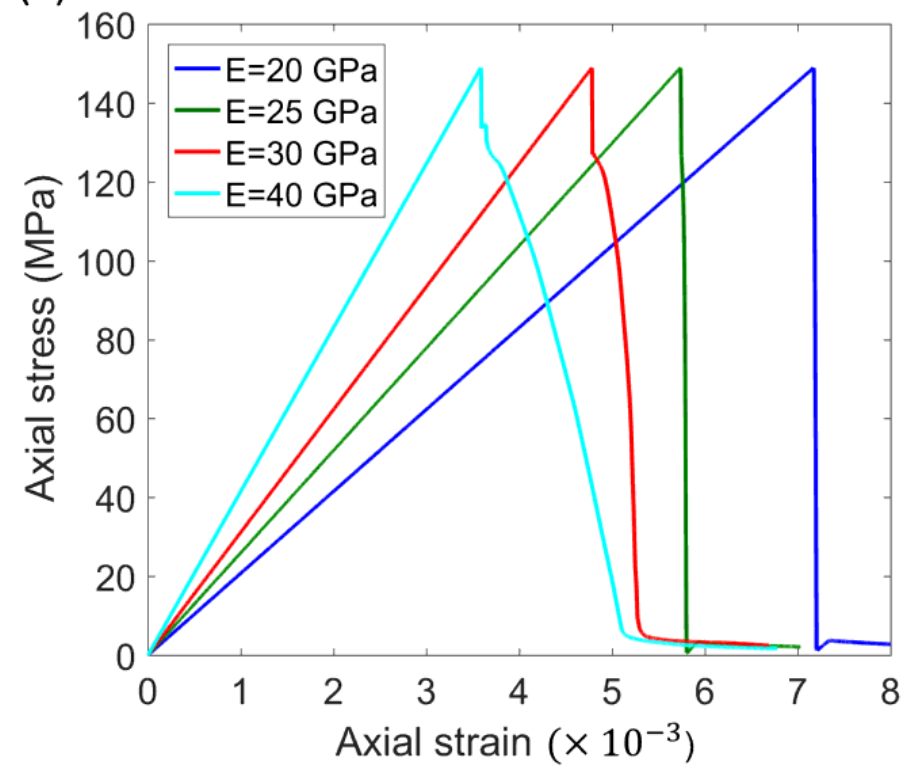

(b)

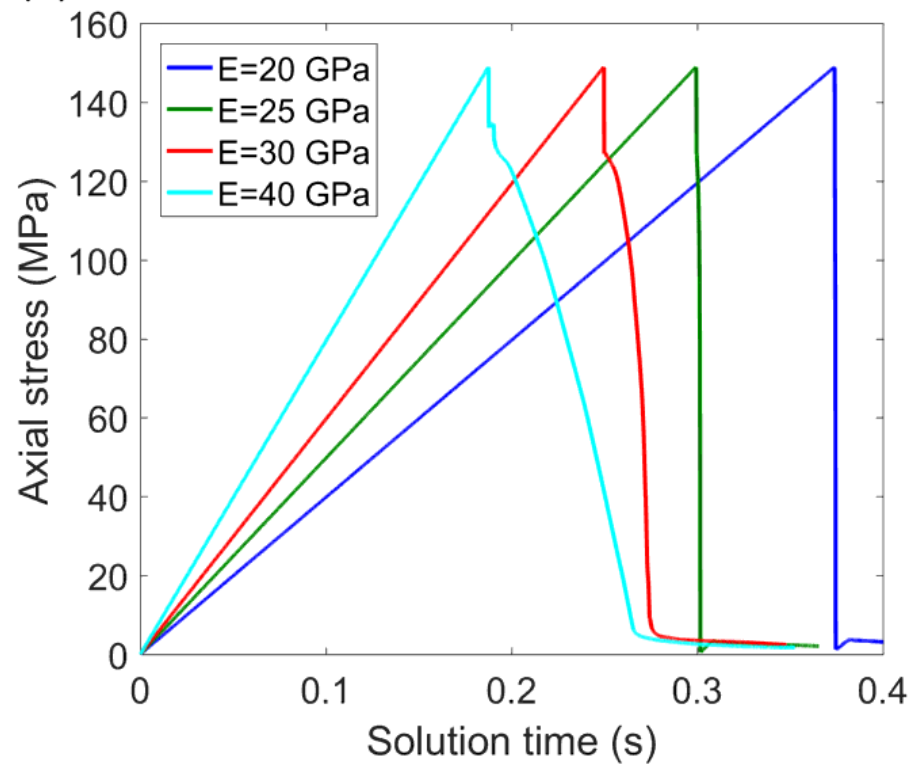

\section{Figure 5}

Stress-strain curves of the Tianhu granite specimen with different Young's modulus values under LSS of infinity. 
(a)

$\mathrm{E}=20 \mathrm{GPa}$

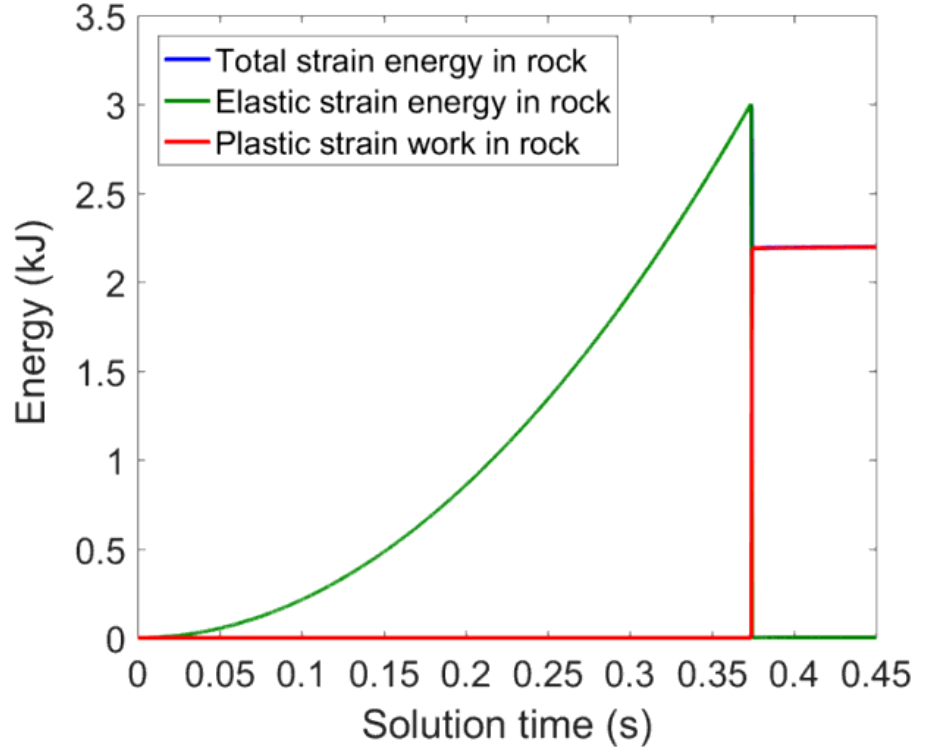

(c)

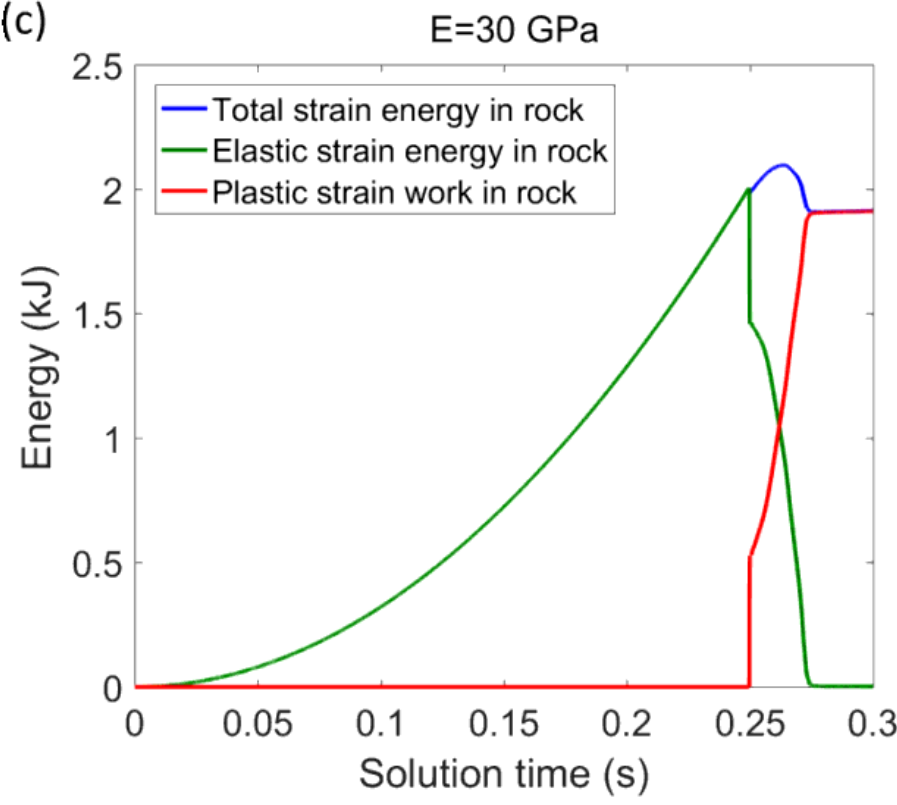

(b) $\mathrm{E}=25 \mathrm{GPa}$

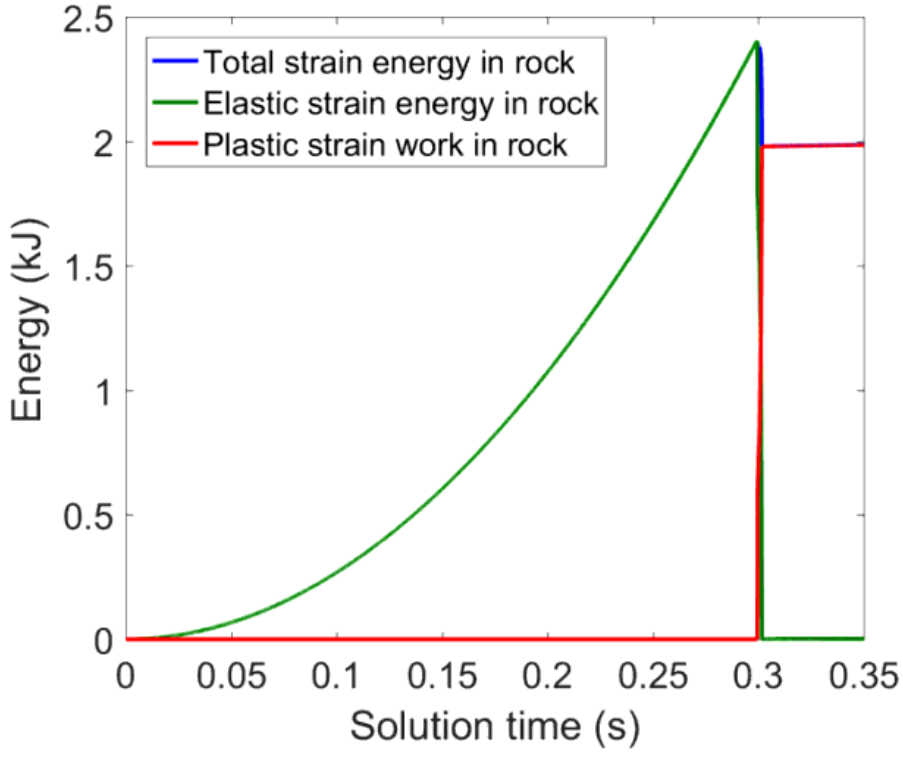

(d)

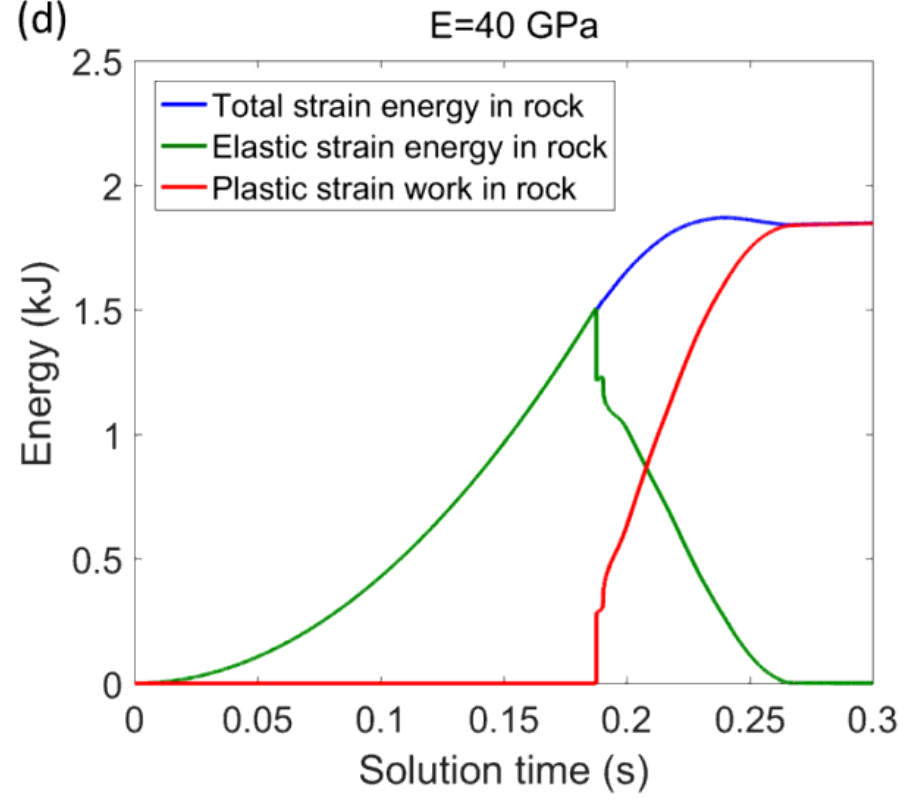

Figure 6

Curves of energy components with solution time in the Tianhu granite specimen for different values of Young's modulus with an LSS of infinity. 


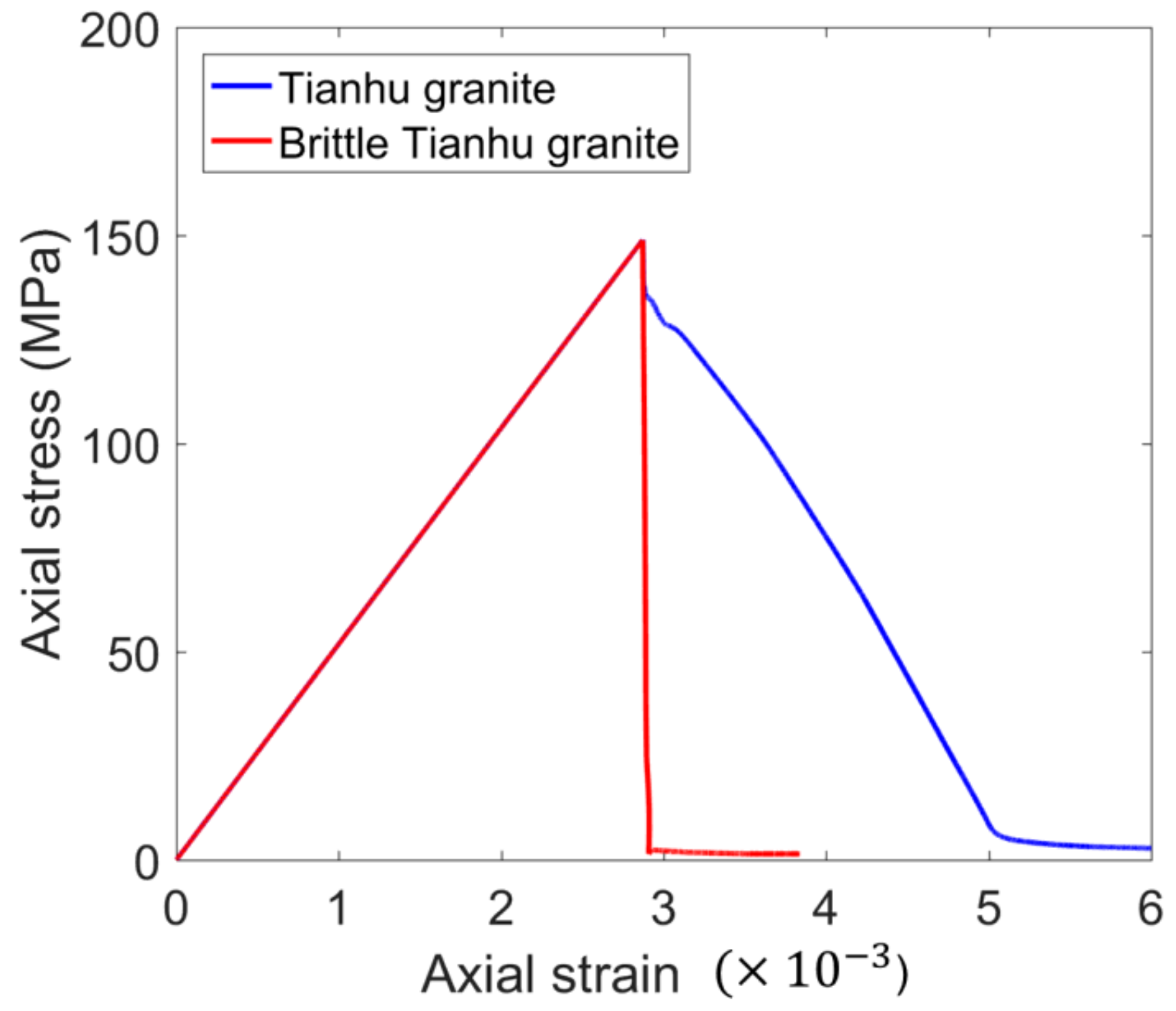

Figure 7

Stress-strain and stress-time curves of the Tianhu granite and brittle Tianhu granite under LSS of infinity. 
(a)

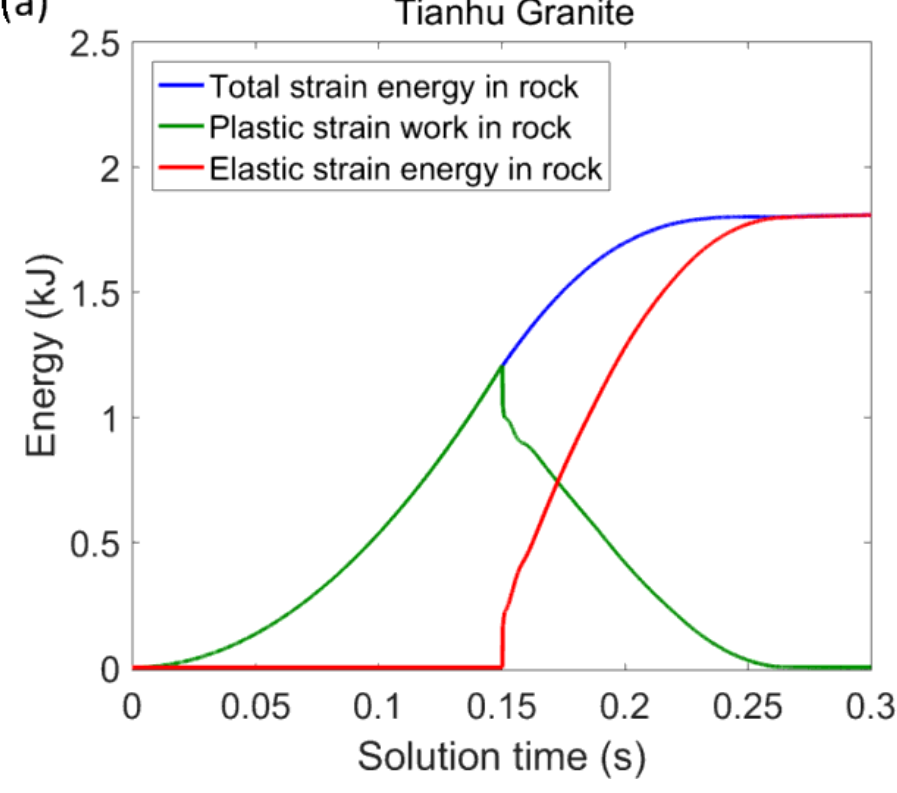

(b)

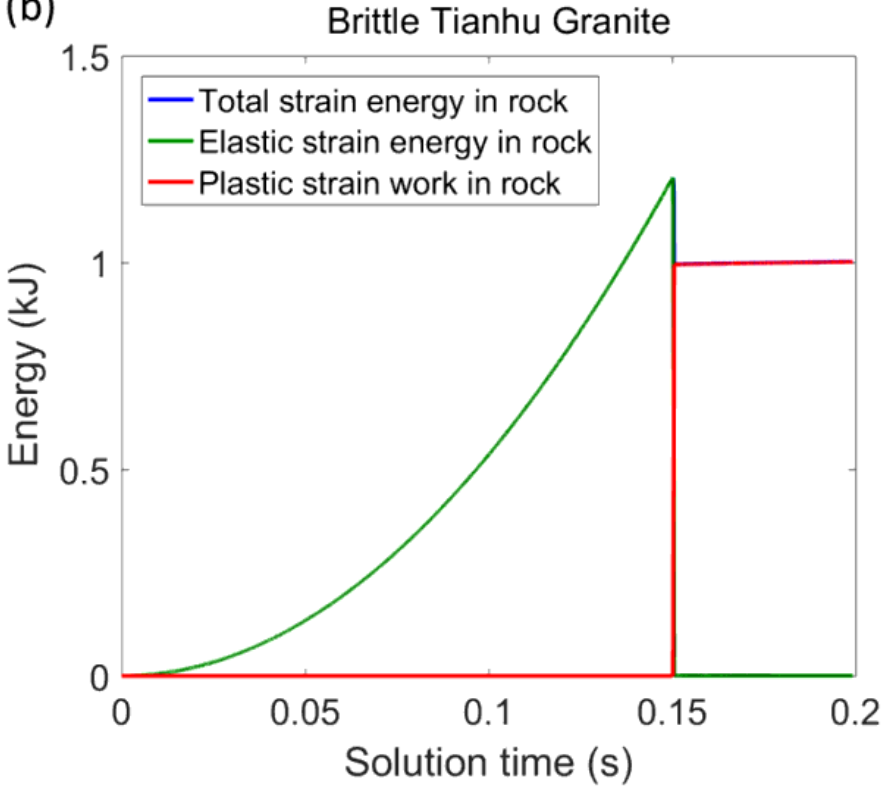

\section{Figure 8}

Curves of energy components with solution time in the Tianhu granite and Brittle Tianhu granite specimens under LSS of infinity. 


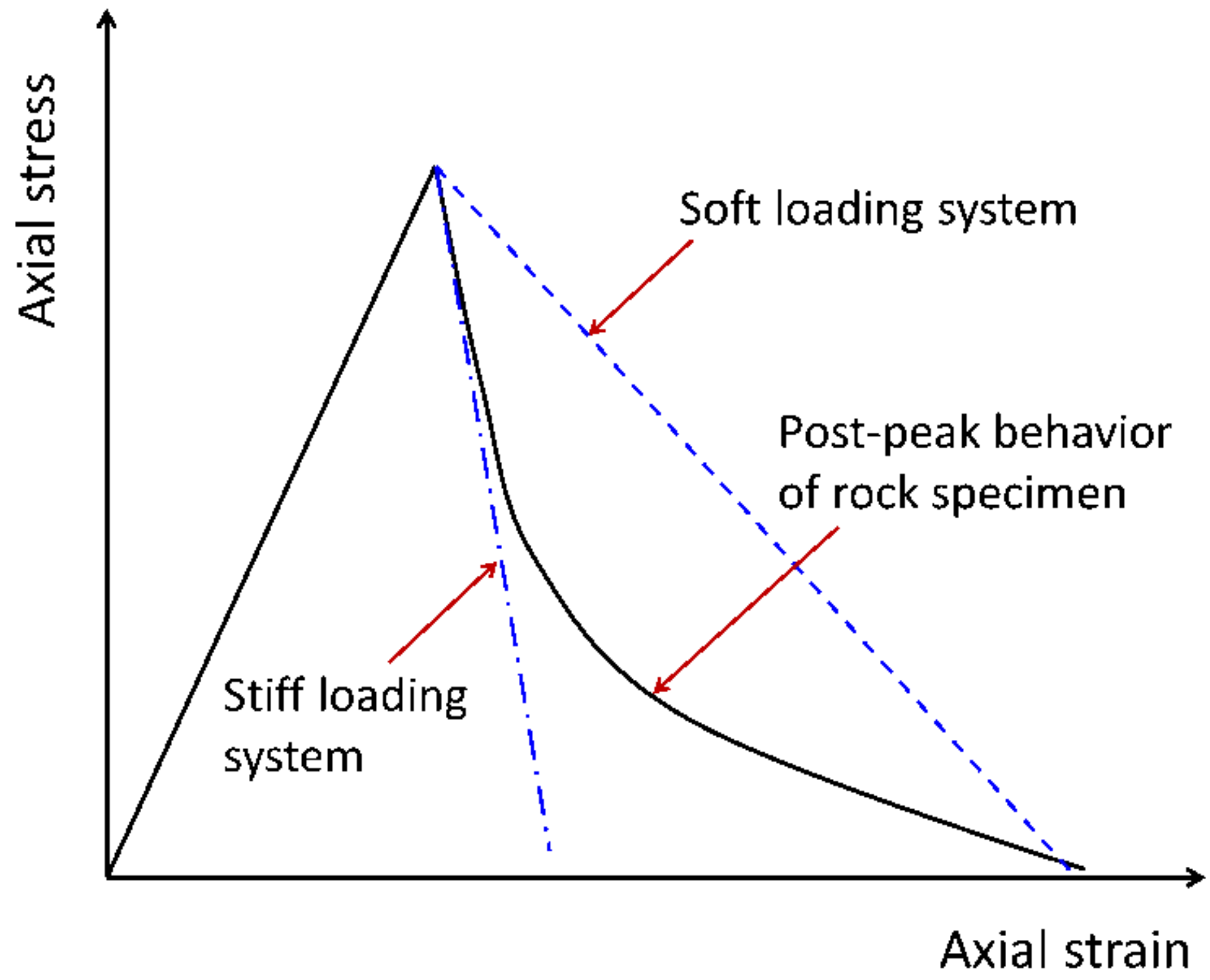

Figure 9

Schematic representation of the physical explanation of stable failure and unstable failure (after Cook, 1965). 


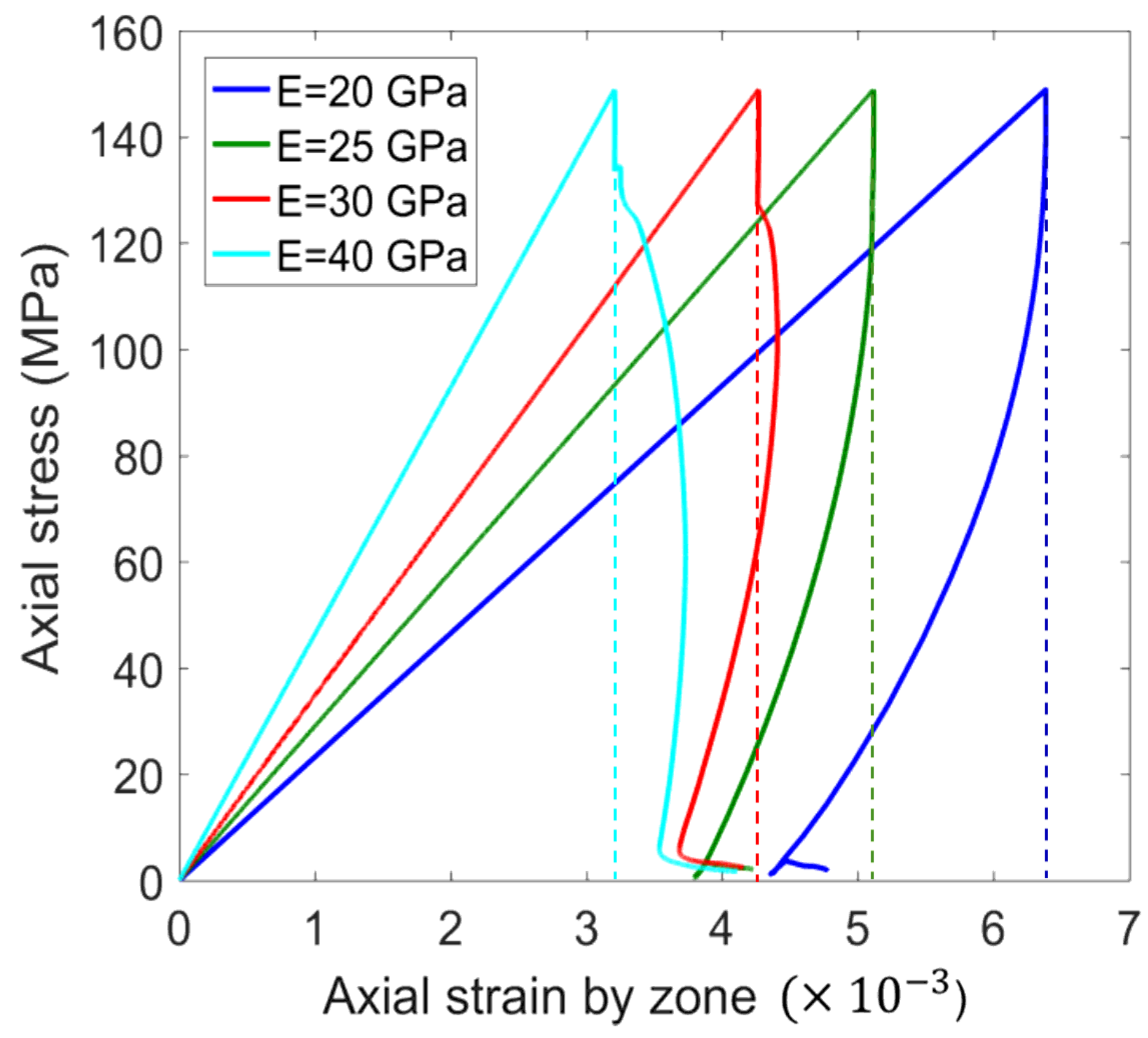

Figure 10

The curves of average stress-strain by zone in the Tianhu granite specimen with Young's modulus values of $20 \mathrm{GPa}, 25 \mathrm{GPa}, 30 \mathrm{GPa}$ and $40 \mathrm{GPa}$. 


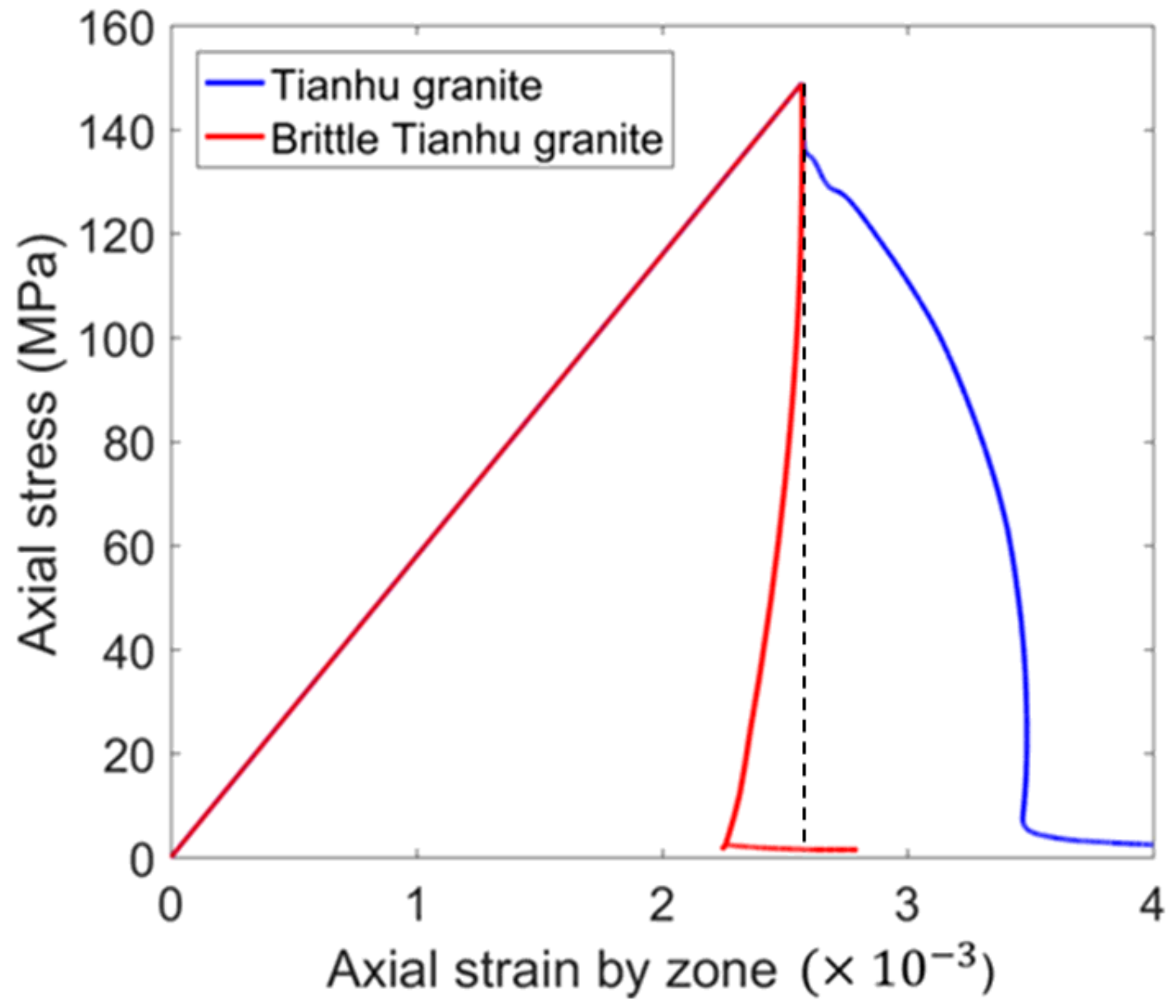

Figure 11

The curves of average stress-strain by zone in the Tianhu granite and Brittle Tianhu granite under LSS of infinity. 